\title{
Non-isothermal melt crystallization kinetics of poly(3-hydroxybutyrate), poly(butylene adipate-co-terephthalate) and its mixture
}

\author{
Anna Raffaela Matos Costa ${ }^{1 *}$ (D), Edson Noryuki Ito ${ }^{1}$, Laura Hecker Cavalho² and Eduardo Luís Canedo 2 \\ 'Programa de Pós-graduação em Ciência e Engenharia de Materiais, Departamento de \\ Engenharia de Materiais, Centro de Tecnologia - CT, Universidade Federal de \\ Rio Grande do Norte - UFRN, Natal, RN, Brasil \\ ${ }^{2}$ Unidade Acadêmica de Engenharia de Materiais - UAEMa, Universidade Federal de \\ Campina Grande - UFCG, Campina Grande, PB, Brasil \\ *raffaela_matos@yahoo.com.br
}

\begin{abstract}
Nonisothermal crystallization and melting of the biodegradable thermoplastics poly(3-hydroxybutyrate) (PHB), poly(butylene adipate-co-terephthalate) (PBAT), and a 1:1 PHB/PBAT blend were investigated by differential scanning calorimetry (DSC) over an extensive range of heating/cooling rates $\left(2\right.$ to $\left.64^{\circ} \mathrm{C} / \mathrm{min}\right)$. The different phase transition behavior of the neat components was reflected in the mixture and suggest an immiscible blend. Pseudo-Avrami, Ozawa and Mo classical macrokinetic models were used to describe the evolution of the melt crystallization process. Results suggest that none of these models could be used to predict the experimental results of crystallization kinetics of the blend with sufficient precision for polymer processing applications. However, some methods may be of used for the neat resins over restricted ranges of cooling rate, temperature or conversion (e.g., Ozawa for PHB at low cooling rate, Mo for PBAT).
\end{abstract}

Keywords: $P H B, P B A T$, blends, crystallization kinetics.

How to cite: Costa, A. R. M., Ito, E. N., Carvalho, L. H., \& Canedo, E. L. (2019). Non-isothermal melt crystallization kinetics of poly(3-hydroxybutyrate), poly(butylene adipate-co-terephthalate) and its mixture. Polímeros: Ciência Tecnologia, 29(1), e2019006. https://doi.org/10.1590/0104-1428.11217

\section{Introduction}

One the most challenging problems of materials technology today is the negative environmental impact of plastic materials. The search of alternative materials and technologies to solve the problem of waste disposal of plastics of petrochemical origin is driving the development of biodegradable polymers ${ }^{[1]}$.

Poly(3-hydroxybutyrate) (PHB) is a biodegradable, biocompatible thermoplastic obtained from renewable natural sources that can be processed with conventional techniques and equipment. However, many applications require an improvement of its properties ${ }^{[2,3]}$. Moreover, widespread commercial use of PHB is limited by its thermal instability during processing, excessive crystallinity and high cost. Poly(butylene adipate-co-terephthalate) (PBAT) is a synthetic random aliphatic-aromatic copolyester with good physical properties which is completely biodegradable in municipal landfills. Moreover, PBAT is a flexible, low-crystallinity thermoplastic, with thermal and mechanical properties similar to some polyethylenes, appropriate for the production of films for the packaging industry. Compared with low density polyethylene (LDPE) films, PBAT films are less permeable to oxygen $(50 \%)$ and much more permeable to water vapor $(80 \times)$, which recommend it for food packaging ${ }^{[3,4]}$. PBAT is relatively stable under processing ${ }^{[5,6]}$. Blending polymers to improve properties and open new fields of application is a common procedure. Thus the development of a fully biodegradable blend PHB/PBAT could be an interesting alternative.

Most industrial processes are conducted under nonisothermal conditions and successful process development involving semicrystalline polymers requires knowledge of the nonisothermal crystallization and meting processes and its kinetics. Although several studies on thermal properties and crystalline structures of PHB and PBAT are available in the technical literature ${ }^{[7-11]}$, very few - if any - considers the kinetics of crystallization PHB/PBAT blends.

Kinetic models of nonisothermal crystallization could be used to predict the evolution of crystallinity as function of time and temperature. The predictive behavior of an analytical model is useful in that the model may be inserted into processing and manufacturing protocols to develop and control processes in which crystallization in one among several concurrent phenomena, e.g., molding, blowing, spinning, etc. ${ }^{[12]}$.

It must be emphasized that the nonisothermal kinetic models available in the literature are all empirical correlation procedures. Model parameters have no physical meaning 
and are not amenable to microstructural interpretation. Nevertheless, they are valuable tools in the hands of process engineers, insofar as they can predict the kinetics of crystallization of real systems under processing conditions

The present contribution is concerned with a thorough investigation of the nonisothermal crystallization and melting behavior of PHB, PBAT, and a blend PHB/PBAT (1:1) by differential scanning calorimetry (DSC), under a wide range of cooling/heating rates $\left(2\right.$ to $\left.64^{\circ} \mathrm{C} / \mathrm{min}\right)$. Classical kinetic models, associated to the names of Avrami, Ozawa, and Mo were used to correlate the experimental data of melt crystallization. The discrepancy between model predictions and experimental data, and range of applicability of the models were discussed in detail.

\section{Materials and Methods}

\subsection{Materials}

Poly(3-hydroxybutyrate (PHB) Biocycle 1000 was supplied by PHB Industrial (Serrana, SP, Brasil), and is actually a copolymer, containing about $4 \%$ units of 3-hydroxyvalerate. Poly (butylene adipate-co-terephthalate) (PBAT) Ecoflex ${ }^{\circledR} \mathrm{F}$ Blend C1200, purchased from BASF (São Paulo SP, Brasil), is basically a linear random 1:1 copolyester; however, a BASF sponsored publication ${ }^{[5]}$ mention small amounts of a third polyfunctional comonomer of unknown chemical structure, which may result is some degree of ramification.

\subsection{Methods}

A blend containing $50 \%$ of PHB and PBAT was compounded in a corotating twin-screw extruder. Samples of neat components were also processed in this way. The extrudates were analyzed by differential scanning calorimetry (DSC) in a Mettler-Toledo DSC-1 instrument. Samples of 5 to $7 \mathrm{mg}$ were heated from $25^{\circ} \mathrm{C}$ to $190{ }^{\circ} \mathrm{C}$ at $24^{\circ} \mathrm{C} / \mathrm{min}$ and kept at that temperature for $1 \mathrm{~min}$; then, there were cooled to $25{ }^{\circ} \mathrm{C}$ at seven different rates, from $2{ }^{\circ} \mathrm{C} / \mathrm{min}$ to $64{ }^{\circ} \mathrm{C} / \mathrm{min}$; after a $3 \mathrm{~min}$ isothermal stage at $25^{\circ} \mathrm{C}$, the samples were reheated to $190{ }^{\circ} \mathrm{C}$ at the same rates. The process was conducted under a flow of nitrogen gas of $50^{\circ} \mathrm{C} / \mathrm{min}$.

Phase transitions (melt crystallization during the cooling stage, cold crystallization and melting during the second heating stage) were identified and analyzed. Conversion $x$ (crystallized or molten fraction of the total transformed mass) was estimated as a function of time integrating the difference between the DSC output $(J)$ and a suitable virtual baseline $\left(J_{0}\right)$ :

$$
x(t)=\frac{1}{E_{0}} \int_{t_{1}}^{t}\left|J\left(t^{\prime}\right)-J_{0}\left(t^{\prime}\right)\right| d t^{\prime}
$$

where

$$
E_{0}=\int_{t_{1}}^{t_{2}}\left|J(t)-J_{0}(t)\right| d t
$$

The rate of conversion was computed as:

$$
c(t)=\frac{d x}{d t}=\frac{\left|J(t)-J_{0}(t)\right|}{E_{0}}
$$

Conversions and rates may be expressed as functions of temperature $T$ during each non-isothermal event conducted at constant cooling/heating rate $\phi=|d T / d t|$ :

$$
T=T_{1} \pm \phi\left(t-t_{1}\right)
$$

where $t_{1}$ and $T_{1}$ are the time and temperature at the onset of the event. Maximum and mean temperatures and rates were estimated from such plots.

The specific heat of phase change $\Delta H$ was computed from the total energy transferred $E_{0}$ (from the sample to the neighborhood during the exothermic crystallization process, vice versa during the endothermic melting process). Mass crystallinity changes were estimated:

$$
\Delta X=\frac{\Delta H}{\Delta H_{m}^{\mathrm{o}}}=\frac{E_{0}}{m_{S} \Delta H_{m}^{\mathrm{o}}}
$$

where $m_{S}$ is the sample mass and $\Delta H^{\circ}{ }_{M}$ is the specific latent heat of melting of $100 \%$ crystalline polymer. For the neat resins values of $146 \mathrm{~J} / \mathrm{g}$ and $114 \mathrm{~J} / \mathrm{g}$ for PHB and PBAT, respectively, taken form the literature (Barham et al, 1984; Gan et al, 2004). For the co-crystallization of the blend, $\Delta H^{\circ}{ }_{M}$ was estimated as a weighted average ${ }^{[13]}$ :

$$
\Delta H_{m}^{0}=\frac{\Delta X_{A}\left(\Delta H_{m}^{0}\right)_{A}+\Delta X_{B}\left(\Delta H_{m}^{0}\right)_{B}}{\Delta X_{A}+\Delta X_{B}}
$$

where $\left(\Delta H^{\circ}{ }_{M}\right)_{A}$ and $\left(\Delta H^{\circ}{ }_{M}\right)_{B}$ are the latent heats of melting of $100 \%$ crystalline components $\mathrm{A}$ and $\mathrm{B}$, and $\Delta X_{A} \mathrm{e} \Delta X_{B}$ are the corresponding crystallinity developed during the separate melting processes of the same sample. Equation (6) takes advantage of different crystallinity exhibited by the two components, and is considered a better alternative than the simple average using mass fractions. However, it assumes independent phase transition processes, with no interference on one component on the crystallization of the other, which may be valid only as a first approximation.

The kinetics of the nonisothermal melt crystallization process was correlated by three classical empirical models, Pseudo-Avrami, Ozawa, and Mo. With the first model, which is called Pseudo-Avrami to distinguish from the well-known Avrami model for isothermal crystallization, the relative crystallinity, estimated at constant cooling rate $\tau$ is expressed as a function of the time since the onset of the event $\tau=t-t_{1}$ as:

$$
x=1-\exp \left(-K \tau^{n}\right)
$$

The parameters $K=K(\phi)$ and $n=n(\phi)$ were determined by linear regression of

$$
y=\ln \left(\ln \frac{1}{1-x}\right)=\ln K+n \ln \tau
$$

For the Ozawa model the relative crystallinity, interpolated from the original data, is correlated in terms of the cooling rate:

$$
x=1-\exp \left(-\kappa \phi^{-m}\right)
$$

The parameters $\kappa=(T)$ e $m=m(T)$ were determined by linear regression: 


$$
y=\ln \left(\ln \frac{1}{1-x}\right)=\ln \kappa-m \ln \phi
$$

using the pairs $(x, \phi)$ previously computed for each value of the temperature $T$.

Finally, for the model attributed to $\mathrm{Mo}^{[1,14]}$ the rate of cooling is expressed as a function of time:

$$
\phi=F \tau^{-\alpha}
$$

based on interpolated data at constant relative crystallinity, estimated from the original results.

The parameters $F=F(x)$ e $\alpha=\alpha(x)$ are obtained by linear regression:

$$
\ln \phi=\ln F-\alpha \ln \tau
$$

using the pairs $(x, \phi)$ previously computed for each value of the relative crystallinity $x$.

Parameters of the three models were correlated in terms of the corresponding independent variable and the discrepancy between predicted and experimental data computed, as a way to establish the usefulness of the models for polymer processing applications.

\section{Results and Discussions}

Figure 1 shows a typical example of heat flow versus time plot (raw DSC results) during the cooling and reheating stages.

Single melt crystallization peaks (C1) were observed for all three samples during the cooling stage, shaper for PBAT, shallower for PHB. Both PHB and the PHAB/PBAT blend further crystallize $(\mathrm{C} 2)$ at the beginning of the reheating stage; no cold crystallization of neat PBAT was observed. An endothermic asymmetric, complex melting peak was observed for neat PHB (at about $30 \mathrm{~min}$ ) and a shallow, simple melting peak for neat PBAT (at about $27 \mathrm{~min}$ ). The blend melts in two separate sub-events, one for the PBAT component and one the PHB. Figure 2 shows the melting behavior (F2) in detail, this time as a function of temperature. PBAT melts as a shallow peak at about $123^{\circ} \mathrm{C}$, both in the neat resin and in the blend; PHB melts as a much larger peak at about $169^{\circ} \mathrm{C}$ (with a shoulder around $156^{\circ} \mathrm{C}$ ), both in the neat resin and in the blend. This observation suggests that both components of crystalize separately, despite the single crystallization peaks observed for the blend.

Several transition parameters were computed from the DSC output integrated according to the procedure described in the previous section. Numerical results for melt and cold crystallization $(\mathrm{C} 1$ and $\mathrm{C} 2)$ and the second melting (F2), for all material and cooling/heating rates tested, are included as Appendix A, Tables A1-A8. Figure 3 show two melt crystallization parameters plotted as functions of the cooling rate: peak temperature and crystallinity. Melt crystallization temperature decreases as the rate of cooling increases, a behavior frequently observed in polymers: less time to crystalize (higher rate of cooling) requires larger super-cooling (lower crystallization temperature) to do the job. No significant dependence on the composition was observed, PHB, PBAT and the blend crystalize at substantially the same temperature. Crystallinity, on the other hand, depends on the nature of the polymer. While the low PBAT crystallinity (around 10 to $15 \%$ ) is realized completely during the cooling stage (no cold crystallization), PHB crystalizes only partially from melt at moderate or high cooling rates; PHB crystallization is completed during the reheating stage. As a consequence, PHB crystallinity from the melt decreases sharply with the cooling rate. The PHB/PBAT blend follows an intermediate way, more influenced by high crystalline component (PHB) behavior.

Both the rate of crystallization and the rate of melting increase with the rate of temperature change. This expected behavior often masks insights on the kinetics of phase transformation. For this reason, the specific rate of phase change, $C=c / \phi$, is introduced. Figure 4 shows its maximum value as a function of the heating/cooling rate for melt

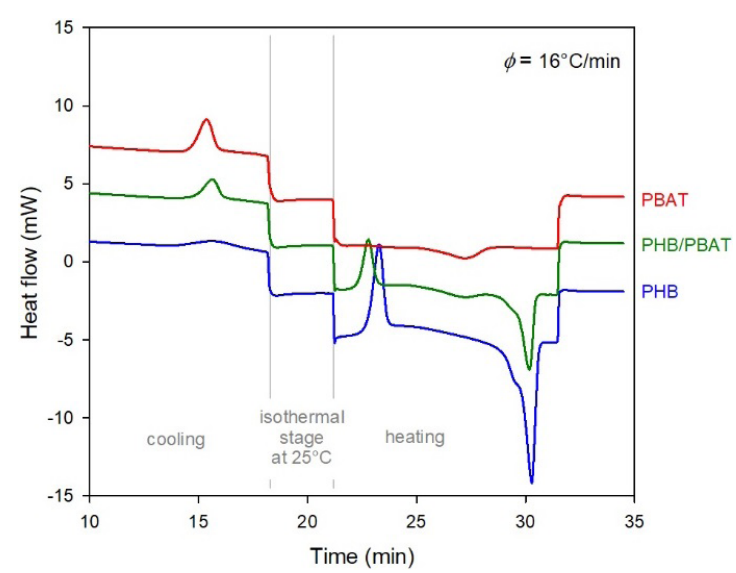

Figure 1. Heat flow versus time for samples of PHB. PBAT and the $\mathrm{PHB} / \mathrm{PBAT}$ blend cooled and reheated at $16^{\circ} \mathrm{C} / \mathrm{min}$ (exothermic peaks up).

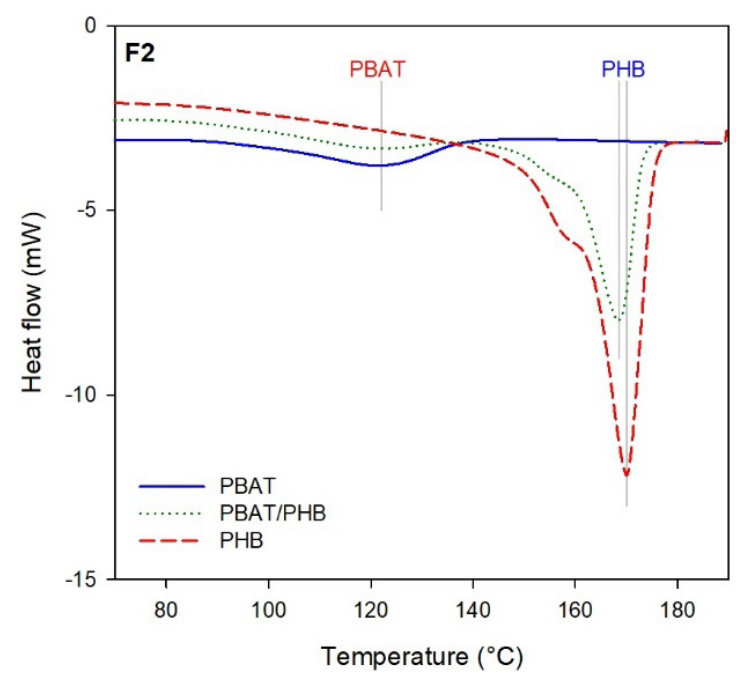

Figure 2. Heat flow versus temperature for the melting events (F2) during reheating at $16^{\circ} \mathrm{C} / \mathrm{min}$. for PBAT. PHB and the PHB/PBAT bled a $16{ }^{\circ} \mathrm{C} / \mathrm{min}$. 

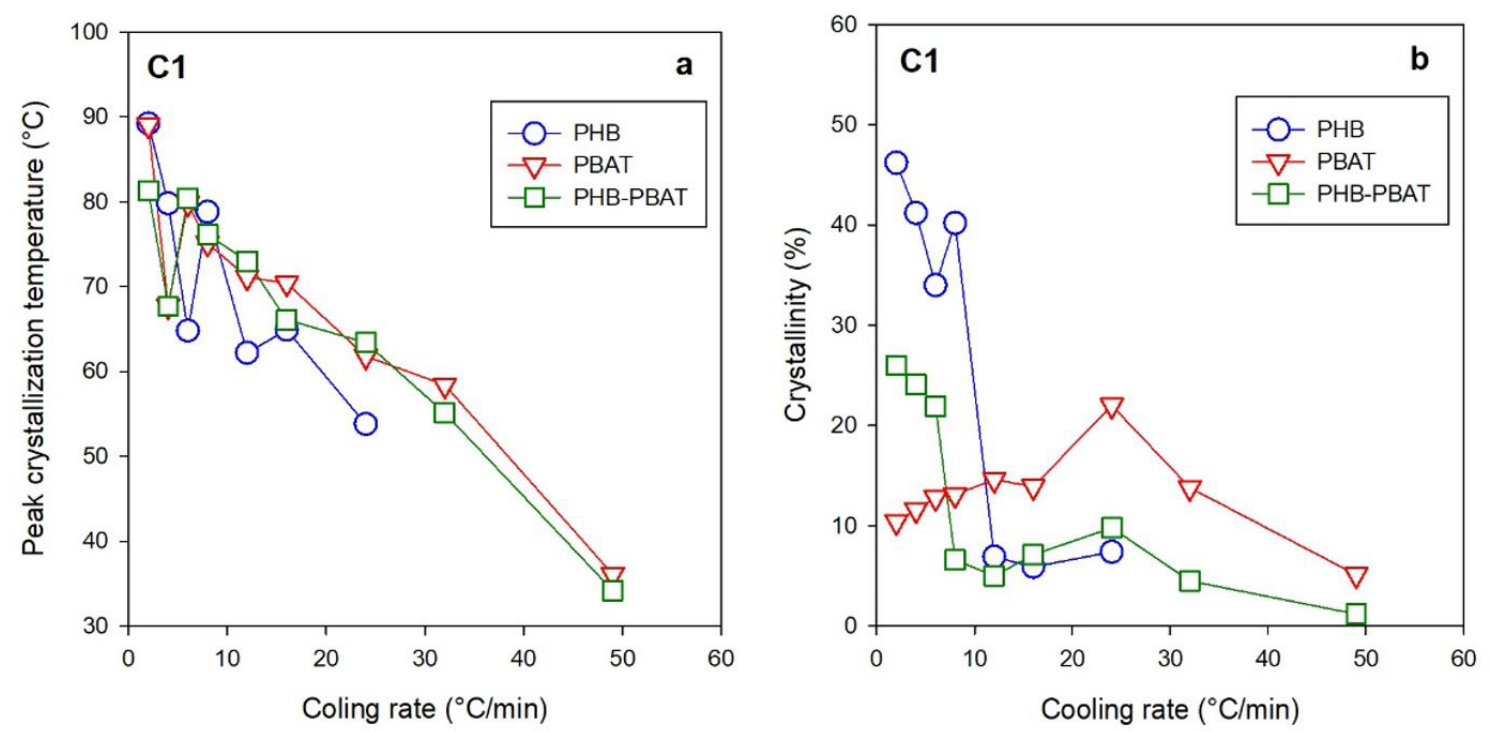

Figure 3. Peak temperature (a) and crystallinity (b) as functions of cooling rate for the melt crystallization of PHB. PBAT and of the PHB/PBAT blend.
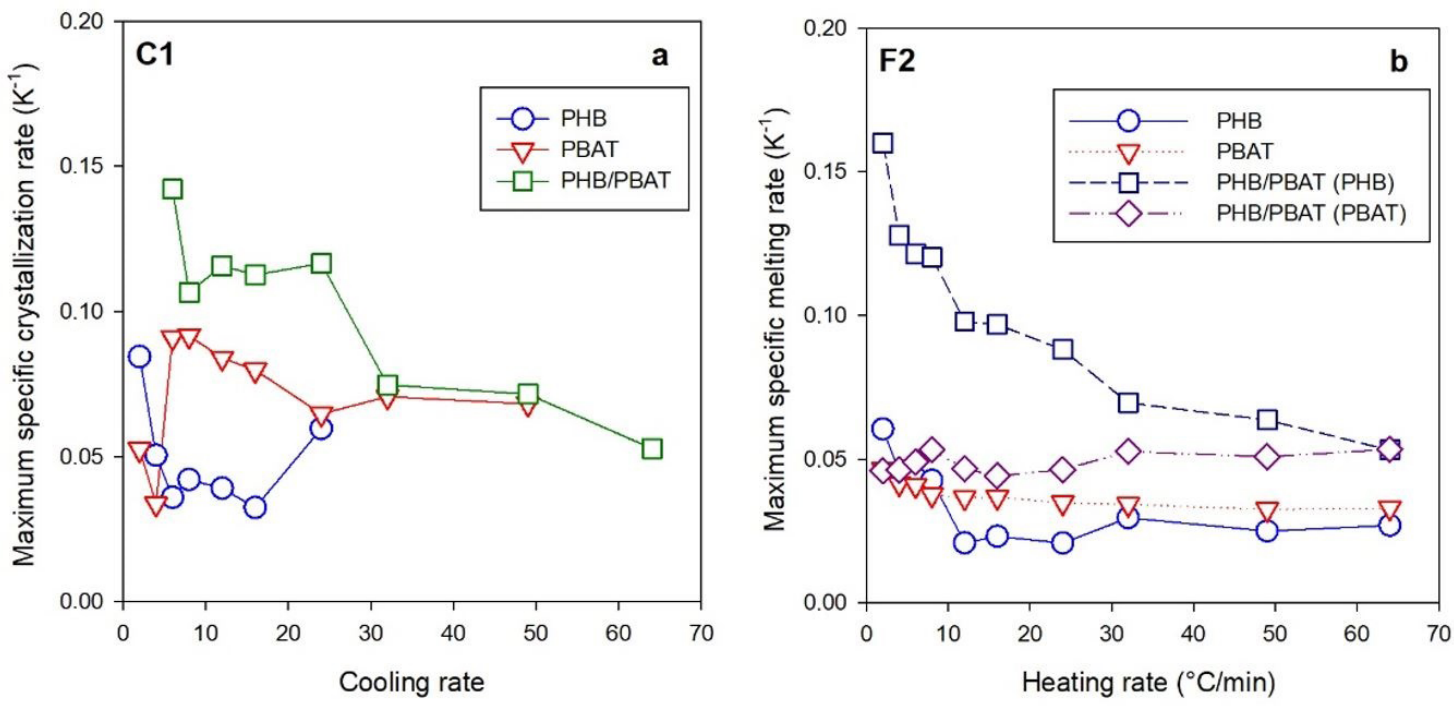

Figure 4. Specific melt crystallization (a) and melting (b) maximum rates for PHB. PBAT and for the PHB/PBAT blend as functions of the cooling/heating rate.

crystallization during the cooling stage $(\mathrm{C} 1)$ and for melting during the reheating stage. Specific rates are less dependent of the material and cooling/heating rate and, for $\phi,>30^{\circ} \mathrm{C} / \mathrm{min}$, become virtually independent of both.

There are few studies of phase transition in PHBV/PBAT blends in the technical literature. Vidharte el al. ${ }^{[15]}$ observed the separate melting of the two components, with a slight rise of the melting points. During cooling, a single melt crystallization peak was observed in the blends, suggesting co-crystallization of PBHV and PBAT. A small increase of the melt crystallization temperature may be attributed to the interference of PBAT on PHB crystal growth. Similar results were reported by Bittmann et al. ${ }^{[16]}$ and are fully consistent with the detailed results discussed in the present work.

\subsection{Kinetics modeling: Pseudo-Avrami}

The relative crystallinity $x$ as a function of time $\tau$ measured from the onset of the melt crystallization event $(\mathrm{C} 1)$ at different cooling rates $\phi$, was correlated using Equation (7) for PHB, PBAT and the PHB/PBAT blend. Figure 5 shows a typical plot of Pseudo Avrami, Equation (8). Parameters $\ln K$ and $n$ computed from a linear regression of the data in the interval $2-98 \%$ relative crystallinity. Numerical results are collected in Tables A9-A11 of the Appendix A. Fitting is excellent, with uncertainty of the parameters below $1 \%$.

This is reflected in a fairly good prediction of the experimental results by the Pseudo-Avrami model, as shown in Figure 6 for neat PBAT. 


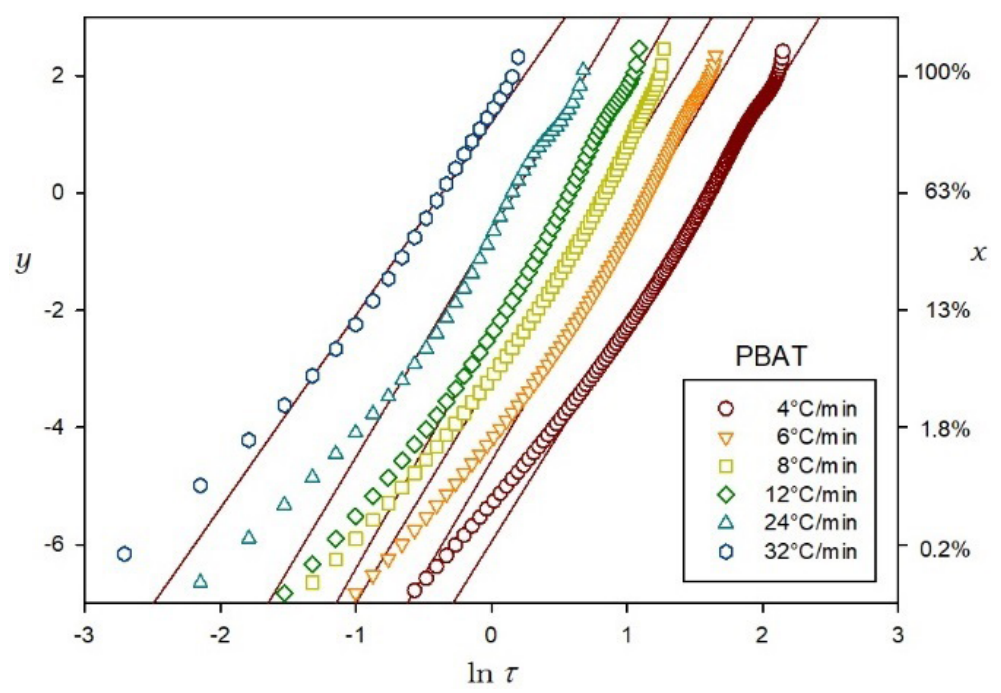

Figure 5. Pseudo-Avrami plot. Equation (8). for the melt crystallization of PBAT at different cooling rates (indicated).

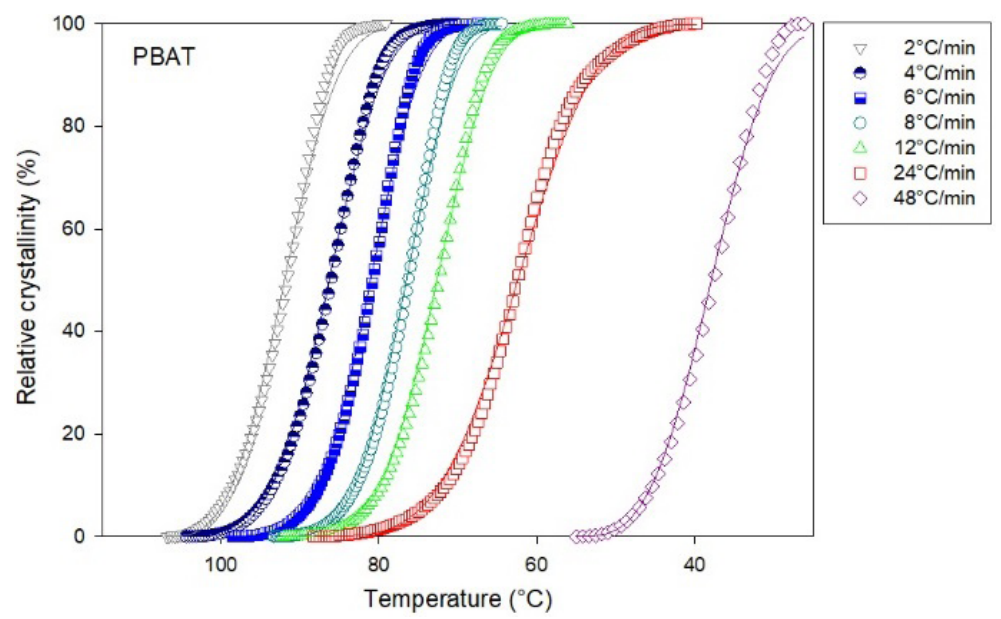

Figure 6. Experimental relative crystallinity (circles) and Pseudo-Avrami model predictions (lines) for the melt crystallization of PBAT.

A better, quantitative picture of the fitting is obtained by plotting the discrepancy between predicted and experimental relative crystallinity $\delta_{x}=x_{\text {pre }}-x_{\text {exp }}$, as shown in Figure 7 for neat PBAT.

Pseudo-Avrami overpredicts relative crystallinity during the first half of the crystallization processes for as much as $4 \%$ and underpredicts relative crystallinity by up to $6 \%$ in last stage of the process. Similar results were obtained with PHB and the PHB/PBAT blend.

These are very good results and Pseudo-Avrami is an excellent choice to correlate experimental data. The problems arise when we try to predict the relative crystallinity for melt crystallization processes conducted at arbitrary rates of cooling. Our purpose, as stated in the Introduction, is to obtain reliable correlations for polymer processing applications, not so much for structural characterization. In this case, an analytical correlation of the model parameters with the cooling rate is needed. Figure 8 shows Pseudo-Avrami parameters as functions of the cooling rate. It is clear that the dispersion of the results precludes the development of such correlation with a reasonably uncertainty. Pseudo-Avrami cannot be recommended polymer processing applications.

\subsection{Kinetics modeling: Ozawa}

Relative crystallinity $x$ as a function of temperature $T$ for the melt crystallization event (C1) in PHB, PBAT and the PHB/PBAT blend were interpolated and correlated as a function of cooling rate $\phi$ using Equation (9). Figure 9 shows a typical Ozawa plot, Equation (10).

Ozawa parameters $\ln \kappa$ and $m$ were computed from a linear regression. Results are collected in Tables A12-A14 of the Appendix A, and shown graphically in Figure 10, along with their uncertainties.

Figure 10 suggest that Ozawa model does not represent experimental data very well and cannot be of use to correlate them, even less to predict them satisfactorily for any application: uncertainties are too high. That is the case in general. However, for neat PHB in the restricted 


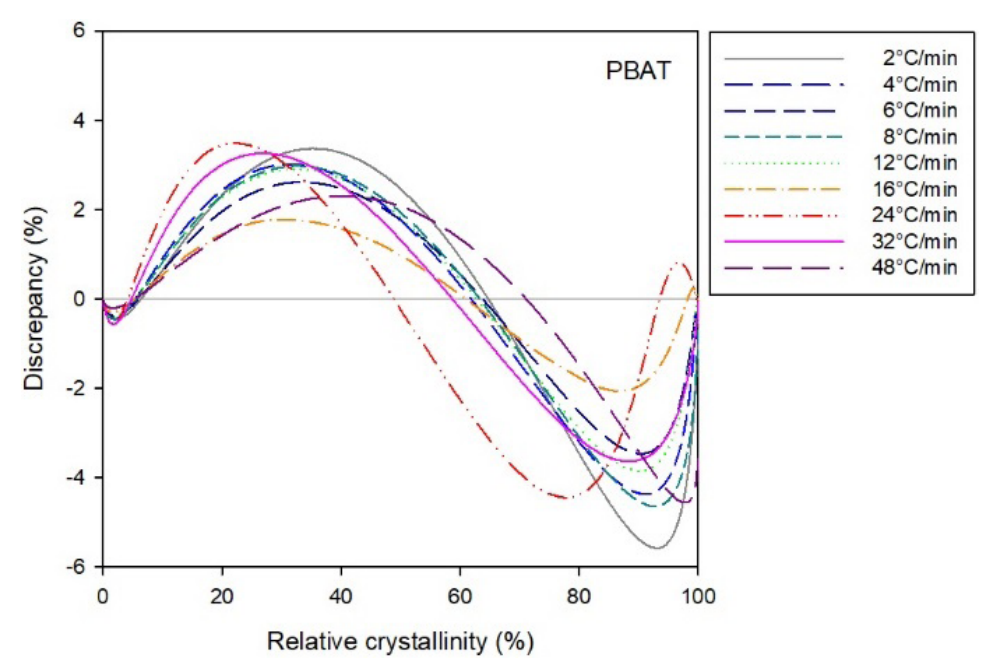

Figure 7. Discrepancy between the Pseudo-Avrami model predictions and the experimental results for the melt crystallization of PBAT as function of relative crystallinity.
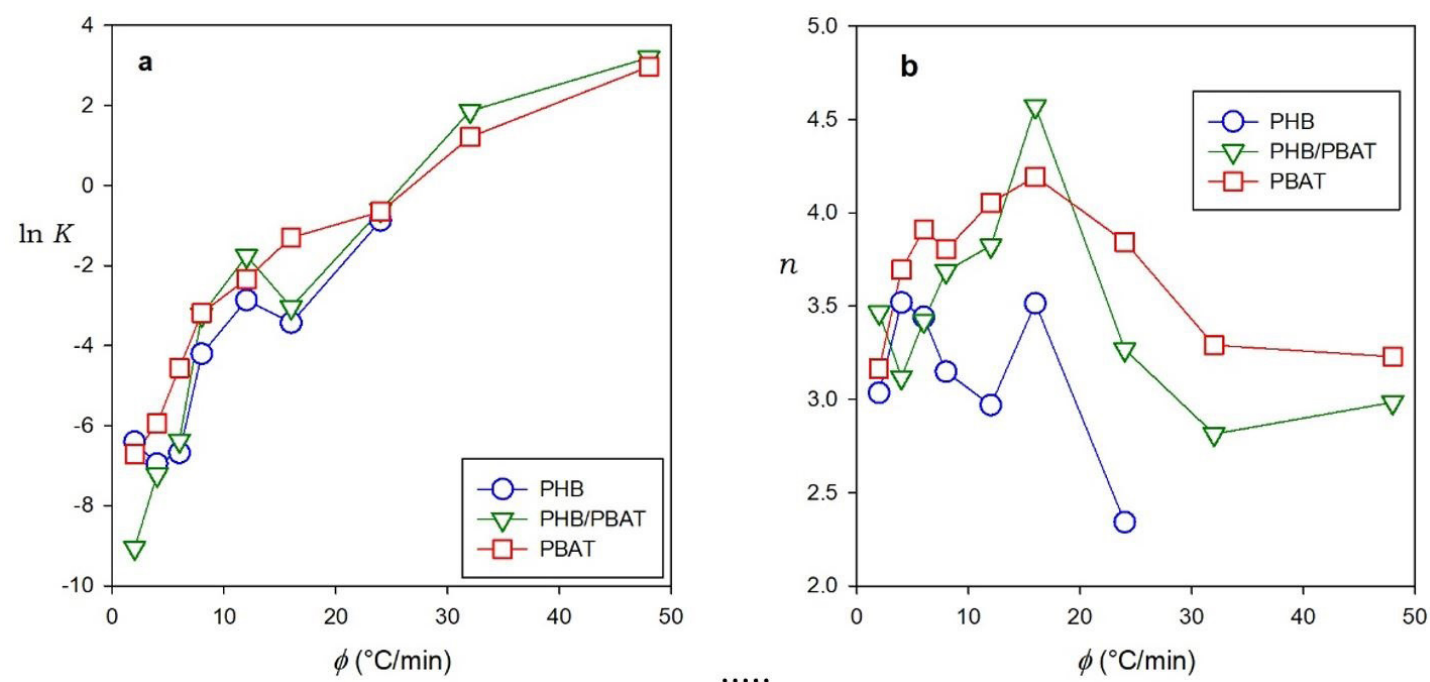

Figure 8. Pseudo-Avrami model parameters $\ln K$ (a) and $n$ (b) for the melt crystallization of PHB. PBAT. and for the PHB/PBAT blend as functions of cooling rate.

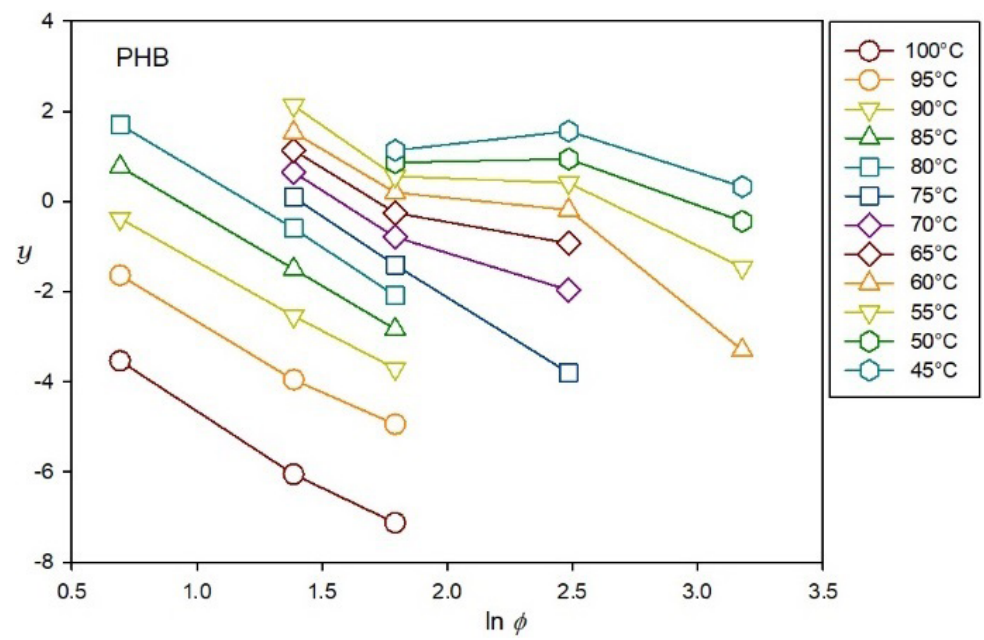

Figure 9. Ozawa plot. Equation (10). for the melt crystallization of PHB at different temperatures (indicated). 

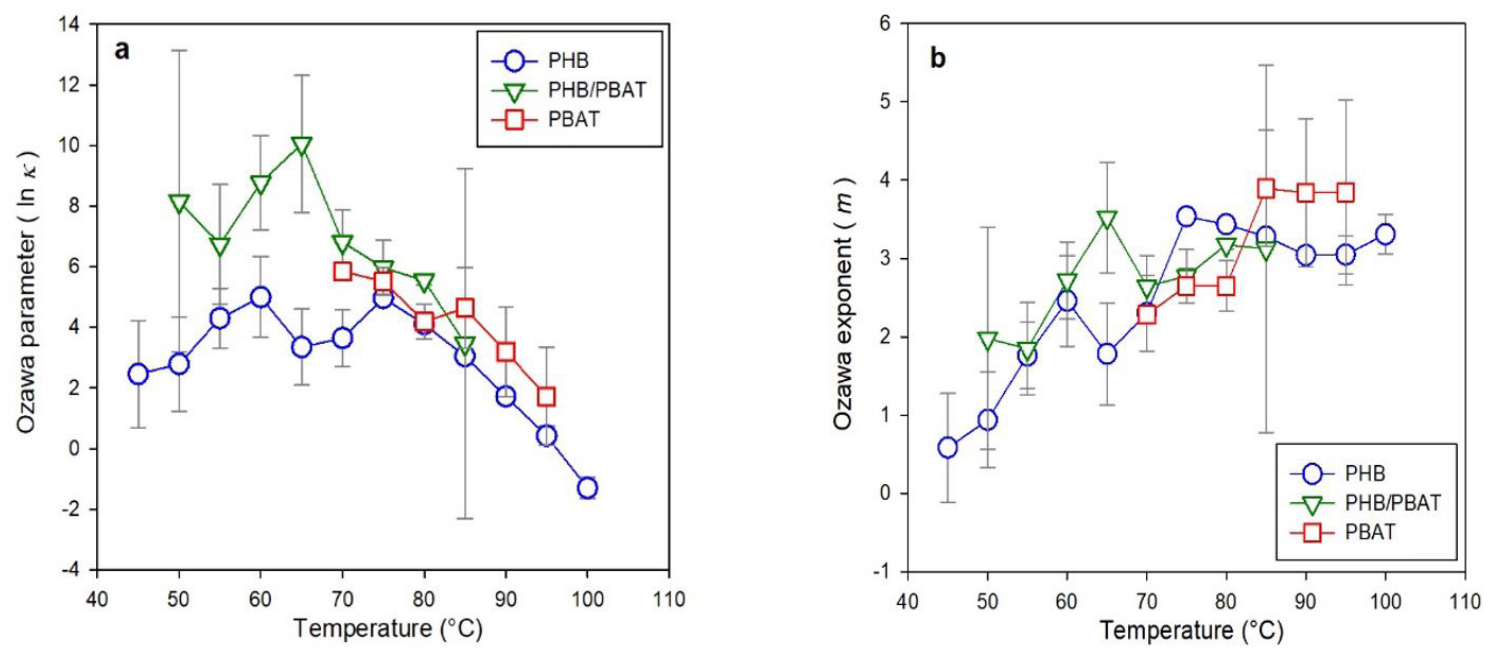

Figure 10. Ozawa model parameters $\ln \mathrm{K}$ (a) and $m$ (b) for the melt crystallization of PHB. PBAT. and for the PHB/PBAT blend as functions of temperature.

temperature interval from $75{ }^{\circ} \mathrm{C}$ to $90^{\circ} \mathrm{C}$ the uncertainty of the parameters is less than $5 \%$ and they can be correlated using a simple quadratic expression:

$$
\begin{aligned}
& \ln \kappa=0,1140 T-0,0001 T^{2} \\
& m=0,3030 T-0,0032 T^{2}
\end{aligned}
$$

as shown in Figure 11.

Fitting is excellent. It turns out that PHB crystallizes from the melt in the reduced temperature interval of $40-100^{\circ} \mathrm{C}$ when cooled at rates equal or less that $6^{\circ} \mathrm{C} / \mathrm{min}$. Figure 12 shows how it performs predicting the values of relative crystallinity versus temperature at low cooling rate.

Ozawa model seems to be perfectly adequate to correlate and predict experimental melt crystallization results for this particular material and cooling rate range. Unpromising models cannot be summarily dismissed without a thorough examination.

\subsection{Kinetics modeling: Mo}

The cooling rate $\phi$ required to reach different values of relative crystallinity at a given time $\tau$ was interpolated for the melt crystallization event (C1) in PHB, PBAT and the PHB/PBAT blend. Cooling rates were correlated with time at constant relative crystallinity using Equation (11). Figure 13 shows a typical Mo plot, Equation (12).

Mo parameters $\ln F$ and $\alpha$ were computed from a linear regression. Results are collected in Tables A15-A17 of the Appendix A, and shown graphically in Figure 14, along with their uncertainties.

Figure 14 shows Mo parameters could be easily and precisely correlated with relative crystallinity by simple polynomial expressions. However, it shows also a significant uncertainty associated to the parameters for PHB and the PHB/PBAT blend; PBAT appears to be the exception. But smoothness and low uncertainty in the parameters not always translates in good predictive behavior. For example, it can be proved (see Appendix B) that Mo model does not

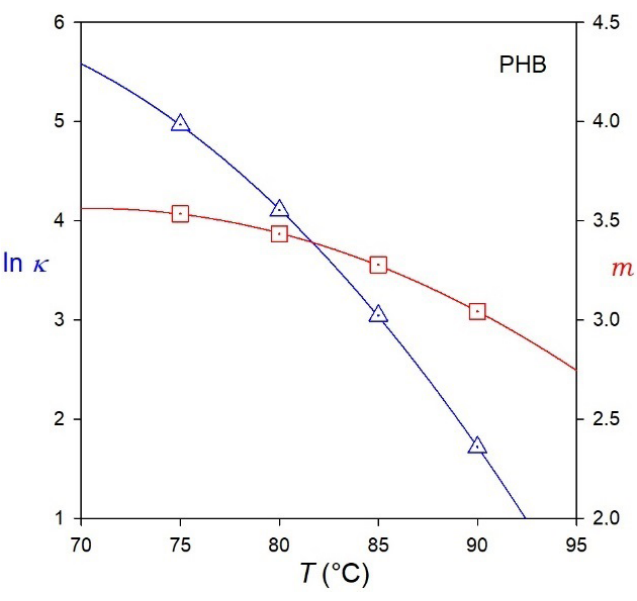

Figure 11. Ozawa model parameters for the melt crystallization of PHB in the interval of $75-90{ }^{\circ} \mathrm{C}$.

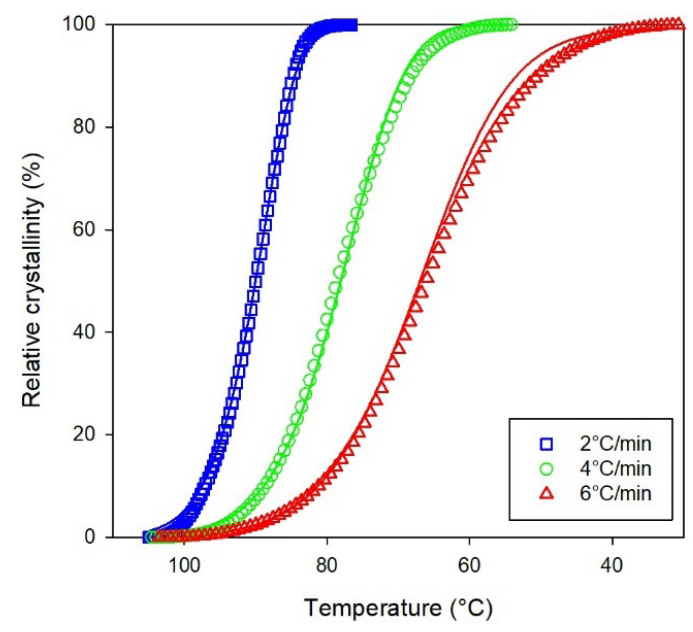

Figure 12. Experimental relative crystallinity (circles) and Ozawa model predictions (lines) for the melt crystallization of PHB at low cooling rates. 


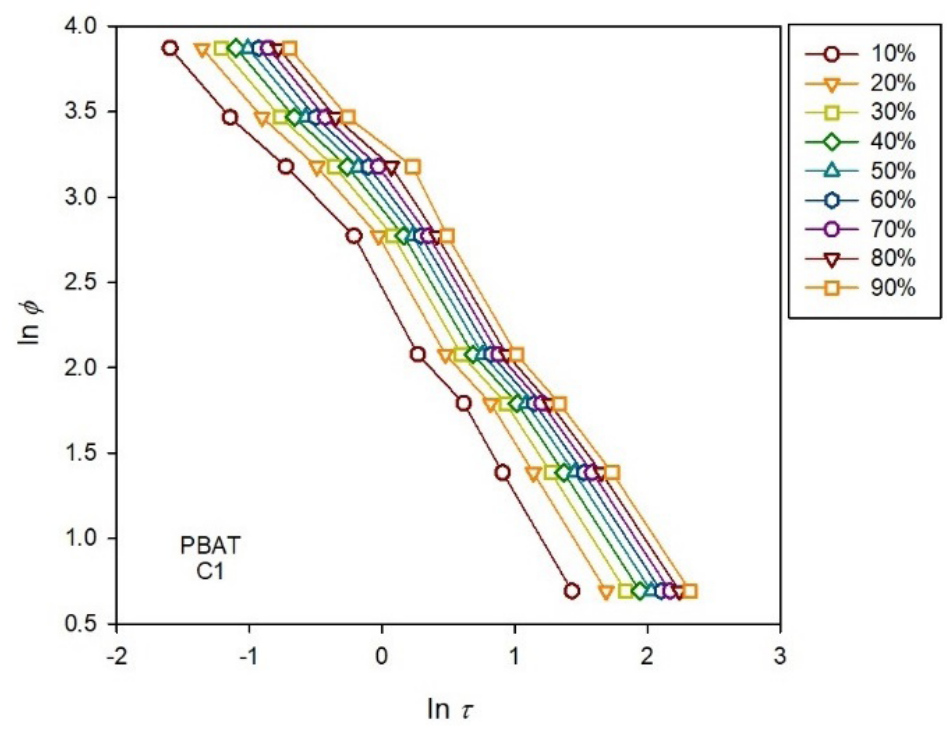

Figure 13. Mo plot. Equation (12). for the melt crystallization of PBAT at different relative crystallinities (indicated).
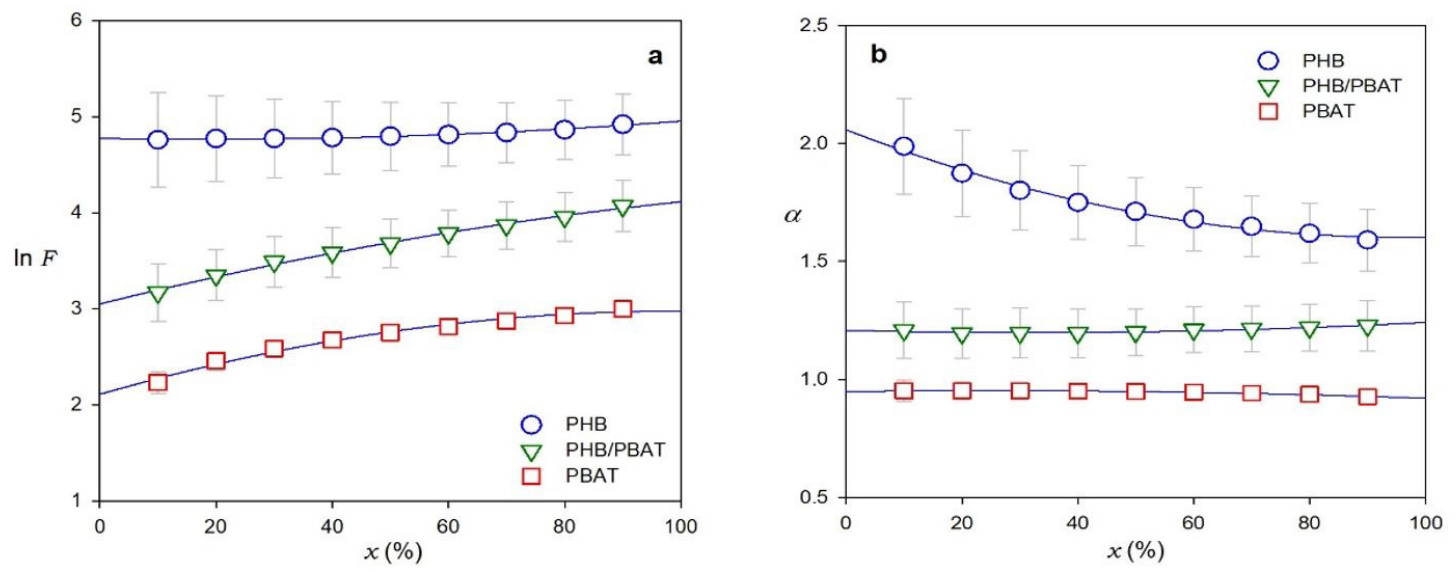

Figure 14. Mo parameters $\ln F(\mathrm{a})$ and $\alpha$ (b) for the melt crystallization of PHB. PBAT. and the PHB/PBAT blend as functions of relative crystallinity.

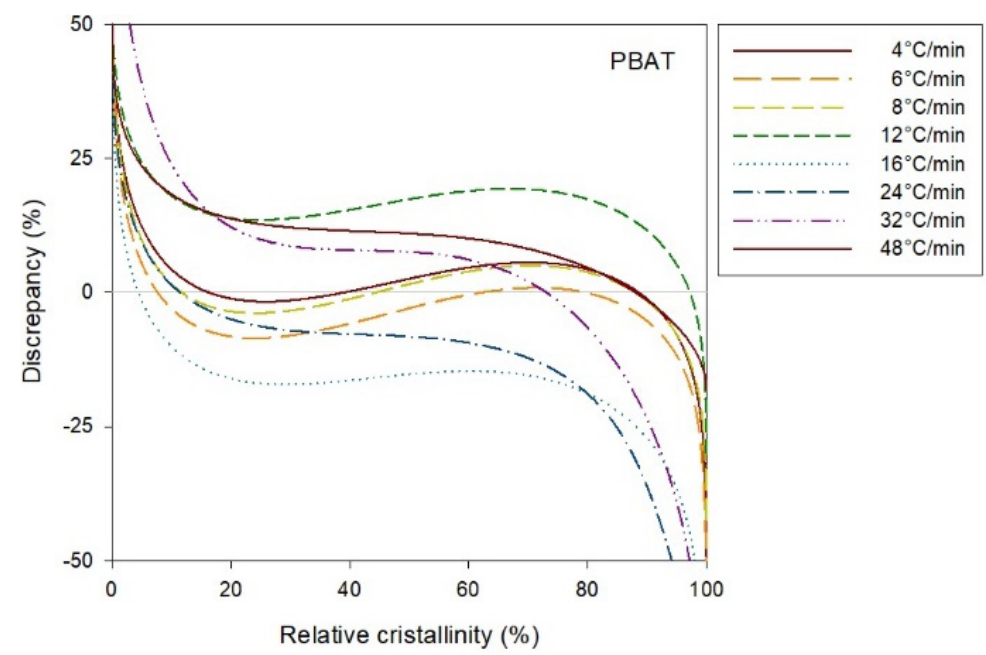

Figure 15. Discrepancy between the Mo model predictions and the experimental results for the melt crystallization of PBAT as function of relative crystallinity. 
lead to a true sigmoid shape of the relative crystallinity versus time or temperature curve, and fails at the beginning of the crystallization process: $c=d x / d \tau \rightarrow 0$ as $\tau \rightarrow 0$ only if $\ln F$ $\rightarrow 0$ as $x \rightarrow 0$, which is not the case, according to Figure 14 .

Discrepancy between experimental results and predictions of Mo model is better expressed in terms of time, which may be estimated inverting Equation (11):

$$
\tau_{\text {pre }}=\left(\frac{F(x)}{\phi}\right)^{1 / \alpha(x)}
$$

Relative discrepancy for a given cooling rate could be defined as a function of relative crystallinity as:

$$
\delta_{\tau}=\frac{\tau_{\text {pre }}-\tau_{\text {exp }}}{\tau_{1 / 2}}
$$

where $\tau_{E X P}$ is the time to reach a relative crystallinity $x$ during a test at a given cooling rate, $\tau_{P R E}$ is computed from Equation (14), and $\tau_{1,}$ is a characteristic time, taken as the half-crystallization time at the cooling rate in question. Figure 15 and 16 shows the discrepancy versus relative crystallinity for the melt crystallization o neat PBAT and the PHB/PBAT blend, respectively.

Figure 15 shows that, even in the best case, neat PBAT, Mo model can only predict the kinetics of the melt crystallization processes with an uncertainty of $\pm 25 \%$ for relative crystallinity between $15 \%$ and $85 \%$. If an application can tolerate that level of uncertainty and limited interval of validity, Mo model is excellent choice. Otherwise, it is not appropriate.

Figure 16 shows that the goodness-of-fit of the Mo model to experimental results of the PHB/PBAT blend is unacceptable for any application. This result couldn't be expected by considering the fitting of Mo parameters, as Figure 14 shows a very smooth behavior. The importance of the discrepancy study, in addition of the parameters fitting - illustrated by a comparison of Figures 14-16 is perhaps the most important contribution of the present work.

\section{Conclusions}

A thorough - albeit limited in scope - study of the PHB/PBAT system by a conventional DSC technique reveals interesting facts of its melting and crystallization behaviour, and of their nonisothermal melt crystallization kinetics.

PHB and PBAT exhibit very different degrees of crystallinity, melting temperatures and peak structures, but these characteristics are independent of the cooling rate and are the same for the neat resins and the blend. Neat PHB crystallizes partially from the melt, even at moderate cooling rates, while PBAT crystallizes completely from the melt at all cooling rates; the blend follows a combined trend that suggests separate crystallizations of the two components. These observations suggest an immiscible, incompatible blend.

None of the three classical kinetic models tested was able to predict the experimental data for the PHB/PBAT blend with acceptable uncertainty. Some models are usable - as predictive tools - for the net components (Ozawa for PHB, Mo for PBAT) over a reduced range of validity. The study confirms the often overlooked fact that good fitting of the model parameters with the available data not always translates in a good predictive behavior, as judged by the discrepancy between model predicted and experimental data.

\section{Acknowledgements}

The authors wish to thank the Conselho Nacional de Pesquisa - CNPq e Coordenação de Aperfeiçoamento de Pessoal Superior - CAPES, Grant \# 473622/2013-0, for financial support.

\section{References}

1. Xiaohui, W., Jun, S., Ying, C., Zhifeng, F., \& Yan, S. (2012). Nonisothermal crystallization kinetics of poly(butylene adipateco-terephthalate) copolyester. China Petroleum Processing and Petrochemical Technology, 14(1), 74-79.

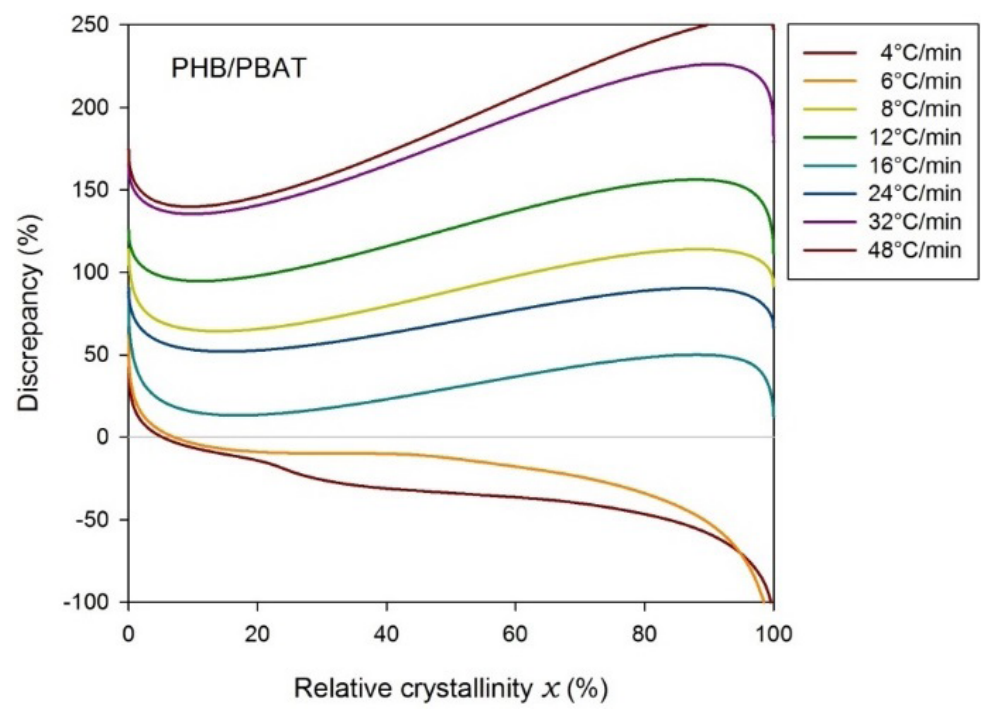

Figure 16. Discrepancy between the Mo model predictions and the experimental results for the melt crystallization of PHB/PBAT blend as function of relative crystallinity. 
2. Fukushima, K., Wu, M. H., Bocchini, S., Rasyida, A., \& Yang, M. C. (2012). PBAT based nanocomposites for medical and industrial applications. Materials Science and Engineering $C$, 32(6), 1331-1351. http://dx.doi.org/10.1016/j.msec.2012.04.005. PMid:24364930.

3. Al-Itry, R., Lamnawar, K., \& Maazouz, A. (2012). Improvement of thermal stability, rheological and mechanical properties of PLA, PBAT and their blends by reactive extrusion with functionalized epoxy. Polymer Degradation \& Stability, 97(10), 1898-1914. http://dx.doi.org/10.1016/j.polymdegradstab.2012.06.028.

4. Barham, P. J., Keller, A., Otun, E. L., \& Holmes, P. A. (1984). Crystallization and morphology of a bacterial thermoplastic: poly-3-hydroxybutyrate. Journal of Materials Science, 19(9), 2781-2789. http://dx.doi.org/10.1007/BF01026954.

5. Yamamoto, M., Witt, U., Skupin, G., Beimborn, D., \& Müller, R. J. (2002). Biodegradable aliphatic-aromatic polyesters: Ecoflex $^{\circledR}$. In Y. Doi, \& A. Steinbüchel (Eds.), Biopolymers, polyesters III - applications and commercial products (pp. 299-305). Weinheim: Wiley-VCH Verlag GmbH.

6. Costa, A. R. M., Almeida, T. G., Silva, S. M. L., Carvalho, L. H., \& Canedo, E. L. (2015). Chain extension in poly(butyleneadipate-terephthalate). Inline testing in a laboratory internal mixer. Polymer Testing, 42, 115-121. http://dx.doi.org/10.1016/j. polymertesting.2015.01.007.

7. Witt, U., Einig, T., Yamamoto, M., Kleeberg, I., Deckwer, W. D., \& Müller, R. J. (2001). Biodegradation of aliphaticaromatic copolyesteres: evaluation of the final biodegradability and ecotoxicological impact of degradation intermediates. Chemosphere, 44(2), 289-299. http://dx.doi.org/10.1016/ S0045-6535(00)00162-4. PMid:11444312.

8. Avérous, L., \& Fringant, C. (2001). Association between plasticized starch and polyesters: processing and performances of injected biodegradable systems. Polymer Engineering and Science, 41(5), 727-734. http://dx.doi.org/10.1002/pen.10768.

9. Gan, Z. H., Kuwabara, K., Yamamoto, M., Abe, H., \& Doi, Y. (2004). Solid-state structures and thermal properties of aliphaticaromatic poly(butylene adipate-co-butylene terephthalate) copolyesters. Polymer Degradation \& Stability, 83(2), 289-300. http://dx.doi.org/10.1016/S0141-3910(03)00274-X.
10. Chen, C., Fei, B., Peng, S., Zhuang, Y., Dong, L., \& Feng, Z. (2002). Nonisothermal crystallization and melting behavior of poly(3-hydroxybutyrate) and maleated poly(3-hydroxybutyrate). European Polymer Journal, 38(80), 1663-1670. http://dx.doi. org/10.1016/S0014-3057(02)00046-0.

11. An, Y., Dong, L., Mo, Z., Liu, T., \& Feng, Z. (1998). Nonisothermal crystallization kinetics of poly( $\beta$-hydoxybutyrate). Journal of Polymer Science. Part B, Polymer Physics, 36(8), 1305-1312. http:// dx.doi.org/10.1002/(SICI)1099-0488(199806)36:8<1305::AIDPOLB5>3.0.CO;2-Q.

12. Schultz, J. M. (2001). Polymer crystallization - the development of crystalline order in thermoplastic polymers. New York: Oxford University Press.

13. Avella, M., Martuscelli, E., Orsello, G., Raimo, M., \& Pascucci, B. (1997). Poly(3- hydroxybutyrate)/poly(methyleneoxide) blends: thermal, crystallization and mechanical behaviour. Polymer, 38(25), 6135-6143. http://dx.doi.org/10.1016/S00323861(97)00166-3.

14. Liu, T., Mo, Z., \& Zhang, H. (1998). Nonisothermal crystallization behavior of a novel poly(aryl ether ketone): PEDEKmK. Journal of Applied Polymer Science, 67(5), 815-821. http://dx.doi. org/10.1002/(SICI)1097-4628(19980131)67:5<815::AIDAPP6>3.0.CO;2-W.

15. Vidhate, S., \& D'Souza, N. A. (2011). Biodegradable poly(hydroxy butyrate-covalerate) nanocomposites and blends with poly(butylene adipate-co-terephthalate) for sensor applications, miscibility, compatibility of PBHV/PBAT blends, (Doctoral thesis). University of North Texas, Texas.

16. Bittmann, B., Bouza, R., Barral, L., Castro-Lopez, M., \& Dopico-Garcia, S. (2015). Morphology and thermal behavior of poly (3-hydroxybutyrate-co-3-hydroxyvalerate)/poly(butylene adipate-co-terephthalate)/clay nanocomposites. Polymer Composites, 36(11), 2051-2058. http://dx.doi.org/10.1002/ pc.23115.

Received: Nov. 19, 2017

Revised: May 19, 2018

Accepted: June 09, 2018 
Appendix A. Crystallization parameters.

The following tables contain a series of parameters for the melt (C1) and cold (C2) crystallization events, and the second melting event (F2), obtained by point-by-point integration of the raw time-temperature-heat flow data reported by the DSC.

$\phi\left({ }^{\circ} \mathrm{C} / \mathrm{min}\right)$ : heating/cooling rate.

T0.1\% $\left({ }^{\circ} \mathrm{C}\right)$ : temperature for $0.1 \%$ molten/crystallized fraction (a good estimate of the initial point of the event).

$\mathrm{T} 50 \%\left({ }^{\circ} \mathrm{C}\right)$ : temperature for $50 \%$ molten/crystallized fraction (a better estimate of the "characteristic" melting/ crystallization temperatures than the peak values, in particular for events represented by complex peaks)

T99.9\% $\left({ }^{\circ} \mathrm{C}\right)$ : temperature for $99.9 \%$ molten/crystallized fraction (a good estimate of the final point of the event)

$\mathrm{Tp},\left({ }^{\circ} \mathrm{C}\right)$ : peak melting/crystallization temperature.

cmax (min-1): maximum melting/crystallization rate.

c5-95\% (min-1): mean melting/crystallization rate for the central $90 \%$ of the polymer.

$\tau_{1 / 2}$ (min): half crystallization time (time to reach $50 \%$ crystallized fraction from the start of the event)

$\Delta \mathrm{H}(\mathrm{J} / \mathrm{g})$ : latent heat of melting/crystallization

$\Delta \mathrm{X}(\%)$ : change in crystallinity during the event (estimated from the latent heats).

Numbers in italic correspond to a minor peak.

Table A1. PHB: melt crystallization (C1).

\begin{tabular}{|c|c|c|c|c|c|c|c|c|c|c|}
\hline$\phi$ & $T_{0,1 \%}$ & $T_{50 \%}$ & $T_{99,9 \%}$ & $\Delta T$ & $T_{p}$ & $\tau_{1 / 2}$ & $c_{\max }$ & $c_{5-95 \%}$ & $\Delta H$ & $\Delta X$ \\
\hline$\left({ }^{\circ} \mathrm{C} / \mathrm{min}\right)$ & & & $\left({ }^{\circ} \mathrm{C}\right)$ & & & $(\min )$ & \multicolumn{2}{|c|}{$\left(\min ^{-1}\right)$} & $(\mathrm{J} / \mathrm{g})$ & $(\%)$ \\
\hline 2 & 103.6 & 90.0 & 78.4 & 25.1 & 89.2 & 6.82 & 0.169 & 0.117 & 67.4 & 46.2 \\
\hline 4 & 101.2 & 78.3 & 51.2 & 49.9 & 79.8 & 5.73 & 0.202 & 0.131 & 60.1 & 41.2 \\
\hline 6 & 99.6 & 66.1 & 31.4 & 68.3 & 64.8 & 5.59 & 0.216 & 0.135 & 35.2 & 24.1 \\
\hline 8 & 105.7 & 80.9 & 50.4 & 55.4 & 78.8 & 3.11 & 0.337 & 0.227 & 58.7 & 40.2 \\
\hline 12 & 87.7 & 61.8 & 37.7 & 50.0 & 62.2 & 2.16 & 0.470 & 0.331 & 10.0 & 6.9 \\
\hline 16 & 100.2 & 66.2 & 40.7 & 59.5 & 64.9 & 2.12 & 0.520 & 0.376 & 8.6 & 5.9 \\
\hline 24 & 88.0 & 58.3 & 32.6 & 55.5 & 53.8 & 1.24 & 1.433 & 0.544 & 10.8 & 7.4 \\
\hline 32 & & & & & & & & & & \\
\hline 48 & \multirow{2}{*}{\multicolumn{10}{|c|}{ (event not observed) }} \\
\hline 64 & & & & & & & & & & \\
\hline
\end{tabular}

Table A2. PHB: cold crystallization (C2).

\begin{tabular}{|c|c|c|c|c|c|c|c|c|c|c|}
\hline$\phi$ & $T_{0,1 \%}$ & $T_{50 \%}$ & $T_{99,9 \%}$ & $\Delta T$ & $T_{p}$ & $\tau_{1 / 2}$ & $c_{\max }$ & $c_{5-95 \%}$ & $\Delta H$ & $\Delta X$ \\
\hline$\left({ }^{\circ} \mathrm{C} / \mathrm{min}\right)$ & & & $\left({ }^{\circ} \mathrm{C}\right)$ & & & $(\min )$ & \multicolumn{2}{|c|}{$\left(\mathrm{min}^{-1}\right)$} & $(\mathrm{J} / \mathrm{g})$ & $(\%)$ \\
\hline 2 & \multirow{2}{*}{\multicolumn{10}{|c|}{ (event not observed) }} \\
\hline 4 & & & & & & & & & & \\
\hline 6 & 38.1 & 48.8 & 54.4 & 18.3 & 49.6 & 1.77 & 0.853 & 0.547 & 15.2 & 10.4 \\
\hline 8 & \multicolumn{10}{|c|}{ (event not observed) } \\
\hline 12 & 44.3 & 57.3 & 66.8 & 22.5 & 58.1 & 1.07 & 1.390 & 0.896 & 29.1 & 19.9 \\
\hline 16 & 43.8 & 57.6 & 67.7 & 23.9 & 58.4 & 0.85 & 1.802 & 1.159 & 33.3 & 22.8 \\
\hline 24 & 52.1 & 62.6 & 69.5 & 17.3 & 63.4 & 0.43 & 2.798 & 1.920 & 32.2 & 22.0 \\
\hline 32 & 51.2 & 69.4 & 96.4 & 45.2 & 69.7 & 0.56 & 2.392 & 1.289 & 48.6 & 33.3 \\
\hline 48 & 55.0 & 72.5 & 86.0 & 30.9 & 73.4 & 0.36 & 3.506 & 2.362 & 36.8 & 25.2 \\
\hline 64 & 58.3 & 80.5 & 101.2 & 42.9 & 80.9 & 0.34 & 3.382 & 2.270 & 43.9 & 30.1 \\
\hline
\end{tabular}


Table A3. PHB: melting (F2).

\begin{tabular}{|c|c|c|c|c|c|c|c|c|c|}
\hline$\phi$ & $T_{0.1 \%}$ & $T_{50 \%}$ & $T_{99.9 \%}$ & $\Delta T$ & $T_{p}$ & $c_{\max }$ & $c_{5-95 \%}$ & $\Delta H$ & $\Delta X$ \\
\hline$\left({ }^{\circ} \mathrm{C} / \mathrm{min}\right)$ & & & $\left({ }^{\circ} \mathrm{C}\right)$ & & & \multicolumn{2}{|c|}{$\left(\min ^{-1}\right)$} & $(J / g)$ & $(\%)$ \\
\hline \multirow{2}{*}{2} & \multirow{2}{*}{148.3} & \multirow{2}{*}{169.6} & \multirow{2}{*}{173.7} & \multirow{2}{*}{25.4} & 160.2 & 0.066 & \multirow{2}{*}{0.121} & \multirow{2}{*}{64.2} & \multirow{2}{*}{44.0} \\
\hline & & & & & 170.8 & 0.323 & & & \\
\hline \multirow{2}{*}{4} & \multirow{2}{*}{138.6} & \multirow{2}{*}{170.0} & \multirow{2}{*}{175.4} & \multirow{2}{*}{36.8} & 161.2 & 0.103 & \multirow{2}{*}{0.183} & \multirow{2}{*}{76.4} & \multirow{2}{*}{52.3} \\
\hline & & & & & 172.5 & 0.524 & & & \\
\hline 6 & 137.0 & 168.4 & 175.4 & 38.4 & 170.8 & 0.618 & 0.261 & 79.2 & 54.2 \\
\hline \multirow{2}{*}{8} & \multirow{2}{*}{139.3} & \multirow{2}{*}{167.8} & \multirow{2}{*}{175.3} & \multirow{2}{*}{36.1} & 160.6 & 0.315 & \multirow{2}{*}{0.341} & \multirow{2}{*}{73.7} & \multirow{2}{*}{50.4} \\
\hline & & & & & 171.1 & 0.836 & & & \\
\hline 12 & 97.0 & 166.6 & 176.5 & 79.6 & 170.5 & 0.970 & 0.250 & 82.3 & 56.4 \\
\hline 16 & 99.4 & 165.6 & 176.9 & 77.5 & 170.0 & 1.202 & 0.371 & 83.7 & 57.4 \\
\hline 24 & 102.4 & 165.5 & 180.8 & 78.4 & 169.9 & 1.417 & 0.499 & 80.7 & 55.3 \\
\hline 32 & 128.1 & 164.6 & 180.2 & 52.1 & 168.1 & 1.737 & 0.947 & 69.5 & 47.6 \\
\hline 48 & 117.3 & 162.0 & 180.3 & 62.9 & 166.7 & 2.331 & 1.223 & 70.0 & 48.0 \\
\hline 64 & 127.8 & 163.1 & 183.7 & 55.9 & 166.9 & 3.100 & 1.724 & 67.8 & 46.4 \\
\hline
\end{tabular}

Table A4. PBAT: melt crystallization (C1).

\begin{tabular}{|c|c|c|c|c|c|c|c|c|c|c|}
\hline$\phi$ & $T_{0.1 \%}$ & $T_{50 \%}$ & $T_{99.9 \%}$ & $\Delta T$ & $T_{p}$ & $\tau_{1 / 2}$ & $c_{\max }$ & $c_{5-95 \%}$ & $\Delta H$ & $\Delta X$ \\
\hline$\left({ }^{\circ} \mathrm{C} / \mathrm{min}\right)$ & & & $\left({ }^{\circ} \mathrm{C}\right)$ & & & (min) & \multicolumn{2}{|c|}{$\left(\mathrm{min}^{-1}\right)$} & $(\mathrm{J} / \mathrm{g})$ & $(\%)$ \\
\hline 2 & 105.7 & 91.6 & 80.2 & 25.5 & $\begin{array}{l}89.5 \\
81.3\end{array}$ & 7.05 & $\begin{array}{l}0.105 \\
0.111\end{array}$ & 0.119 & 11.8 & 10.4 \\
\hline 4 & 102.2 & 86.0 & 71.8 & 30.4 & $\begin{array}{l}85.7 \\
67.7\end{array}$ & 4.05 & $\begin{array}{l}0.089 \\
0.135\end{array}$ & 0.214 & 13.2 & 11.6 \\
\hline 6 & 96.4 & 80.8 & 68.7 & 27.7 & 79.8 & 2.61 & 0.546 & 0.357 & 14.6 & 12.8 \\
\hline 8 & 91.4 & 76.3 & 65.9 & 25.4 & 75.1 & 1.89 & 0.733 & 0.489 & 14.9 & 13.1 \\
\hline 12 & 89.6 & 72.4 & 58.5 & 31.1 & 71.1 & 1.44 & 1.008 & 0.654 & 16.6 & 14.6 \\
\hline 16 & 88.3 & 71.4 & 55.8 & 32.5 & 70.4 & 1.06 & 1.278 & 0.839 & 15.8 & 13.9 \\
\hline 24 & 85.7 & 62.4 & 41.6 & 44.2 & 61.8 & 0.97 & 1.555 & 0.868 & 25.1 & 22.0 \\
\hline 32 & 75.9 & 59.2 & 45.7 & 30.2 & 58.4 & 0.52 & 2.263 & 1.544 & 15.7 & 13.8 \\
\hline 48 & 53.2 & 37.6 & 27.2 & 26.1 & 36.1 & 0.33 & 3.344 & 2.472 & 5.77 & 5.1 \\
\hline 64 & \multicolumn{10}{|c|}{ (isothermal crystallization $@ 25^{\circ} \mathrm{C}$ ) } \\
\hline
\end{tabular}

Table A5. PBAT: melting (F2).

\begin{tabular}{|c|c|c|c|c|c|c|c|c|c|}
\hline$\phi$ & $T_{0.1 \%}$ & $T_{50 \%}$ & $T_{99.9 \%}$ & $\Delta T$ & $T_{p}$ & $c_{\max }$ & $c_{5-95 \%}$ & \multirow{2}{*}{$\begin{array}{c}\Delta H \\
(\mathrm{~J} / \mathrm{g}) \\
\end{array}$} & \multirow{2}{*}{$\begin{array}{c}\Delta X \\
(\%)\end{array}$} \\
\hline$\left({ }^{\circ} \mathrm{C} / \mathrm{min}\right)$ & & & $\left({ }^{\circ} \mathrm{C}\right)$ & & & \multicolumn{2}{|c|}{$\left(\mathrm{min}^{-1}\right)$} & & \\
\hline 2 & 100.4 & 123.1 & 140.0 & 39.6 & 125.7 & 0.093 & 0.065 & 7.2 & 6.3 \\
\hline 4 & 94.4 & 121.6 & 146.4 & 52.0 & 124.2 & 0.166 & 0.113 & 9.3 & 8.2 \\
\hline 6 & 92.8 & 120.7 & 141.6 & 48.9 & 123.2 & 0.245 & 0.167 & 10.0 & 8.8 \\
\hline 8 & 86.9 & 118.5 & 141.6 & 54.8 & 121.2 & 0.301 & 0.204 & 11.6 & 10.2 \\
\hline 12 & 86.2 & 118.7 & 144.1 & 58.0 & 121.3 & 0.439 & 0.298 & 12.4 & 10.9 \\
\hline 16 & 85.7 & 118.5 & 143.3 & 57.6 & 121.5 & 0.588 & 0.395 & 11.8 & 10.4 \\
\hline 24 & 83.8 & 117.6 & 142.0 & 58.2 & 120.7 & 0.837 & 0.573 & 13.7 & 12.0 \\
\hline 32 & 82.6 & 117.0 & 142.3 & 59.7 & 120.0 & 1.097 & 0.742 & 13.0 & 11.4 \\
\hline 48 & 84.4 & 119.6 & 146.8 & 62.4 & 122.4 & 1.594 & 1.090 & 14.1 & 12.4 \\
\hline 64 & 85.2 & 121.1 & 149.1 & 63.9 & 123.8 & 2.112 & 1.430 & 11.4 & 10.0 \\
\hline
\end{tabular}


Table A6. PHB/PBAT blend: melt crystallization (C1).

\begin{tabular}{|c|c|c|c|c|c|c|c|c|c|c|}
\hline$\phi$ & $T_{0.1 \%}$ & $T_{50 \%}$ & $T_{99.9}$ & $\Delta T$ & $T_{p}$ & $\tau_{1 / 2}$ & $c_{\max }$ & $c_{5-95 \%}$ & \multirow{2}{*}{$\begin{array}{c}\Delta H \\
(\mathrm{~J} / \mathrm{g}) \\
\end{array}$} & \multirow{2}{*}{$\begin{array}{l}\Delta X \\
(\%)\end{array}$} \\
\hline$\left({ }^{\circ} \mathrm{C} / \mathrm{min}\right)$ & & & \multicolumn{3}{|l|}{$\left({ }^{\circ} \mathrm{C}\right)$} & (min) & \multicolumn{2}{|c|}{$\left(\min ^{-1}\right)$} & & \\
\hline \multirow{2}{*}{2} & \multirow{2}{*}{108.1} & \multirow{2}{*}{86.3} & \multirow{2}{*}{66.8} & \multirow{2}{*}{41.3} & 89.5 & \multirow{2}{*}{10.90} & 0.105 & \multirow{2}{*}{0.075} & \multirow{2}{*}{36.9} & \multirow{2}{*}{26.0} \\
\hline & & & & & 81.3 & & 0.111 & & & \\
\hline \multirow{2}{*}{4} & \multirow{2}{*}{103.0} & \multirow{2}{*}{70.5} & \multirow{2}{*}{39.4} & \multirow{2}{*}{63.6} & 85.7 & \multirow{2}{*}{8.14} & 0.089 & \multirow{2}{*}{0.086} & \multirow{2}{*}{34.4} & \multirow{2}{*}{24.1} \\
\hline & & & & & 67.7 & & 0.133 & & & \\
\hline \multirow{2}{*}{6} & \multirow{2}{*}{102.7} & \multirow{2}{*}{75.2} & \multirow{2}{*}{32.1} & \multirow{2}{*}{70.6} & 80.4 & \multirow{2}{*}{4.59} & 0.238 & \multirow{2}{*}{0.132} & \multirow{2}{*}{31.3} & \multirow{2}{*}{21.9} \\
\hline & & & & & 71.3 & & 0.158 & & & \\
\hline 8 & 92.8 & 77.1 & 65.6 & 27.2 & 76.1 & 1.96 & 0.681 & 0.446 & 9.1 & 6.6 \\
\hline 12 & 89.1 & 73.9 & 61.5 & 27.5 & 73.0 & 1.27 & 1.020 & 0.684 & 7.1 & 5.0 \\
\hline 16 & 90.4 & 67.6 & 52.4 & 38.0 & 66.1 & 1.42 & 1.203 & 0.751 & 10.2 & 7.1 \\
\hline 24 & 87.4 & 63.7 & 41.7 & 45.7 & 63.4 & 0.99 & 1.263 & 0.746 & 14.0 & 9.8 \\
\hline 32 & 69.8 & 55.9 & 42.5 & 27.3 & 55.1 & 0.43 & 2.362 & 1.668 & 6.4 & 4.5 \\
\hline 48 & 49.9 & 36.0 & 27.0 & 22.9 & 34.2 & 0.29 & 3.726 & 2.768 & 1.8 & 1.2 \\
\hline 64 & \multicolumn{10}{|c|}{ (isothermal crystallization @ $25^{\circ} \mathrm{C}$ ) } \\
\hline
\end{tabular}

Table A7. PHB/PBAT blend: cold crystallization (C2).

\begin{tabular}{|c|c|c|c|c|c|c|c|c|c|c|}
\hline$\phi$ & $T_{0.1 \%}$ & $T_{50 \%}$ & $T_{99.9 \%}$ & $\Delta T$ & $T_{p}$ & $\tau_{1 / 2}$ & $c_{\max }$ & $c_{5-95 \%}$ & $\Delta H$ & $\Delta X$ \\
\hline$\left({ }^{\circ} \mathrm{C} / \mathrm{min}\right)$ & & & $\left({ }^{\circ} \mathrm{C}\right)$ & & & $(\min )$ & \multicolumn{2}{|c|}{$\left(\mathrm{min}^{-1}\right)$} & $(\mathrm{J} / \mathrm{g})$ & $(\%)$ \\
\hline 2 & \multicolumn{10}{|c|}{ (evento não observado) } \\
\hline 4 & 34.6 & 42.4 & 49.4 & 14.8 & 42.9 & 1.70 & 0.690 & 0.449 & 2.4 & 1.7 \\
\hline 6 & 35.8 & 41.8 & 48.2 & 12.4 & 42.1 & 1.01 & 1.041 & 0.722 & 3.9 & 2.7 \\
\hline 8 & 39.4 & 49.0 & 57.8 & 18.4 & 49.4 & 1.21 & 1.093 & 0.714 & 8.7 & 6.3 \\
\hline 12 & 36.3 & 49.4 & 57.2 & 18.9 & 49.9 & 0.92 & 1.667 & 1.072 & 18.9 & 13.3 \\
\hline 16 & 37.0 & 50.1 & 61.4 & 24.5 & 50.6 & 0.81 & 1.859 & 1.177 & 16.2 & 11.3 \\
\hline 24 & 45.9 & 57.8 & 68.5 & 22.5 & 58.2 & 0.49 & 2.708 & 1.763 & 21.2 & 14.9 \\
\hline 32 & 43.3 & 57.4 & 70.4 & 27.0 & 57.9 & 0.43 & 3.080 & 2.006 & 20.4 & 14.3 \\
\hline 48 & 41.8 & 58.4 & 72.1 & 30.3 & 59.1 & 0.34 & 4.011 & 2.607 & 20.0 & 14.0 \\
\hline 64 & 45.9 & 64.6 & 83.1 & 37.1 & 65.0 & 0.29 & 4.389 & 2.793 & 20.5 & 14.3 \\
\hline
\end{tabular}

Table A8. PHB/PBAT bend: melting (F2).

\begin{tabular}{|c|c|c|c|c|c|c|c|c|c|c|}
\hline & & $T_{0.1 \%}$ & $T_{50 \%}$ & $T_{99.9 \%}$ & $\Delta T$ & $T_{p}$ & $c_{\max }$ & $c_{5-95 \%}$ & \multirow{2}{*}{$\begin{array}{c}\Delta H \\
(\mathrm{~J} / \mathrm{g})\end{array}$} & \multirow{2}{*}{$\begin{array}{c}\Delta X \\
(\%)\end{array}$} \\
\hline \multicolumn{2}{|c|}{$\left({ }^{\circ} \mathrm{C} / \mathrm{min}\right)$} & \multicolumn{5}{|c|}{$\left({ }^{\circ} \mathrm{C}\right)$} & \multicolumn{2}{|c|}{$\left(\min ^{-1}\right)$} & & \\
\hline \multirow[b]{2}{*}{2} & PBAT & 98.1 & 123.3 & 139.8 & 41.7 & 126.5 & 0.092 & 0.063 & 7.5 & 6.6 \\
\hline & PHB & 152.9 & 170.1 & 174.6 & 21.7 & $\begin{array}{l}160.5 \\
171.4\end{array}$ & $\begin{array}{l}0.041 \\
0.320\end{array}$ & 0.132 & 64.6 & 44.3 \\
\hline \multirow[b]{2}{*}{4} & PBAT & 97.5 & 121.9 & 137.5 & 40.0 & 124.6 & 0.185 & 0.130 & 7.3 & 6.4 \\
\hline & PHB & 145.2 & 169.3 & 174.7 & 29.5 & $\begin{array}{l}152.2 \\
171.2\end{array}$ & $\begin{array}{l}0.017 \\
0.512\end{array}$ & 0.223 & 81.8 & 56.1 \\
\hline \multirow[b]{2}{*}{6} & PBAT & 97.6 & 120.0 & 134.8 & 37.2 & 122.0 & 0.294 & 0.206 & 3.1 & 2.7 \\
\hline & PHB & 145.4 & 168.1 & 174.1 & 28.7 & $\begin{array}{l}159.8 \\
170.3\end{array}$ & $\begin{array}{l}0.152 \\
0.728\end{array}$ & 0.322 & 37.4 & 25.6 \\
\hline \multirow{2}{*}{8} & PBAT & 105.7 & 122.1 & 137.8 & 32.1 & 122.3 & 0.427 & 0.323 & 6.0 & 5.3 \\
\hline & PHB & 144.1 & 168.2 & 174.5 & 29.9 & 170.4 & 0.963 & 0.430 & 58.5 & 40.1 \\
\hline \multirow{2}{*}{12} & PBAT & 94.3 & 119.1 & 135.1 & 40.8 & 121.6 & 0.560 & 0.386 & 7.27 & 6.4 \\
\hline & PHB & 142.0 & 167.2 & 175.5 & 32.5 & 169.6 & 1.175 & 0.559 & 71.8 & 49.2 \\
\hline \multirow{2}{*}{16} & PBAT & 92.6 & 117.0 & 133.7 & 41.2 & 118.6 & 0.708 & 0.503 & 8.5 & 7.4 \\
\hline & PHB & 141.6 & 165.9 & 174.7 & 33.1 & 168.4 & 1.550 & 0.750 & 61.4 & 42.0 \\
\hline \multirow{2}{*}{24} & PBAT & 95.0 & 118.8 & 134.3 & 39.2 & 120.7 & 1.113 & 0.817 & 6.55 & 5.7 \\
\hline & PHB & 142.4 & 167.1 & 178.3 & 35.8 & 169.9 & 2.116 & 1.059 & 69.5 & 47.6 \\
\hline \multirow{2}{*}{32} & PBAT & 100.2 & 117.0 & 130.6 & 30.5 & 118.4 & 1.686 & 1.319 & 4.6 & 4.0 \\
\hline & PHB & 139.2 & 164.6 & 177.4 & 38.2 & 167.7 & 2.228 & 1.273 & 65.5 & 44.8 \\
\hline \multirow{2}{*}{48} & PBAT & 95.4 & 116.6 & 129.6 & 34.2 & 117.4 & 2.494 & 1.875 & 4.3 & 3.8 \\
\hline & PHB & 137.1 & 162.5 & 177.1 & 40.0 & 166.1 & 3.120 & 1.863 & 62.4 & 42.8 \\
\hline \multirow{2}{*}{64} & PBAT & 100.0 & 118.6 & 133.2 & 33.3 & 119.3 & 3.420 & 2.587 & 3.8 & 3.3 \\
\hline & PHB & 139.3 & 164.2 & 181.3 & 42.0 & 167.6 & 3.404 & 2.302 & 56.9 & 39.0 \\
\hline
\end{tabular}


Costa, A. R. M., Ito, E. N., Cavalho, L. H., \& Canedo, E. L.

Table A9. Pseudo-Avrami parameters for PHB (C1)

\begin{tabular}{|c|c|c|c|c|c|c|c|}
\hline \multirow{2}{*}{$\phi\left({ }^{\circ} \mathrm{C} / \mathrm{min}\right)$} & \multicolumn{3}{|c|}{$\ln K$} & \multicolumn{3}{|c|}{$n$} & \multirow{2}{*}{$R^{2}$} \\
\hline & & \pm & $\%$ & & \pm & $\%$ & \\
\hline 2 & -6.4074 & 0.0203 & 0.3 & 3.0333 & 0.0113 & 0.4 & 0.993 \\
\hline 4 & -6.9572 & 0.0080 & 0.1 & 3.5184 & 0.0045 & 0.1 & 0.999 \\
\hline 6 & -6.6818 & 0.0149 & 0.2 & 3.4410 & 0.0087 & 0.3 & 0.997 \\
\hline 8 & -4.2084 & 0.0043 & 0.1 & 3.1465 & 0.0038 & 0.1 & 0.999 \\
\hline 12 & -2.8648 & 0.0080 & 0.3 & 2.9683 & 0.0099 & 0.3 & 0.998 \\
\hline 16 & -3.4311 & 0.0048 & 0.1 & 3.5135 & 0.0060 & 0.2 & 0.999 \\
\hline 24 & -0.8769 & 0.0105 & 1.2 & 2.3405 & 0.0186 & 0.8 & 0.993 \\
\hline
\end{tabular}

Table A10. Pseudo-Avrami parameters for PBAT (C1).

\begin{tabular}{|c|c|c|c|c|c|c|c|}
\hline \multirow{2}{*}{$\phi\left({ }^{\circ} \mathrm{C} / \mathrm{min}\right)$} & \multicolumn{3}{|c|}{$\ln K$} & \multicolumn{3}{|c|}{$n$} & \multirow{2}{*}{$R^{2}$} \\
\hline & & \pm & $\%$ & & \pm & $\%$ & \\
\hline 2 & -6.7143 & 0.0221 & 0.3 & 3.1626 & 0.0121 & 0.4 & 0.9930 \\
\hline 4 & -5.9399 & 0.0197 & 0.3 & 3.6935 & 0.0146 & 0.4 & 0.996 \\
\hline 6 & -4.5618 & 0.0222 & 0.5 & 3.9119 & 0.0238 & 0.6 & 0.994 \\
\hline 8 & -3.1850 & 0.0173 & 0.5 & 3.8032 & 0.0269 & 0.7 & 0.994 \\
\hline 12 & -2.3419 & 0.0141 & 0.6 & 4.0535 & 0.0309 & 0.8 & 0.995 \\
\hline 16 & -1.3028 & 0.0079 & 0.6 & 4.1928 & 0.2260 & 5.4 & 0.998 \\
\hline 24 & -0.6570 & 0.0179 & 2.7 & 3.8443 & 0.0426 & 1.1 & 0.992 \\
\hline 32 & 1.2063 & 0.0383 & 3.2 & 3.2902 & 0.0461 & 1.4 & 0.992 \\
\hline 48 & 2.9628 & 0.0494 & 1.7 & 3.2293 & 0.3630 & 11.2 & 0.997 \\
\hline
\end{tabular}

Table A11. Pseudo-Avrami parameters for PHB/PBAT blend (C1).

\begin{tabular}{|c|c|c|c|c|c|c|c|}
\hline \multirow{2}{*}{$\phi\left({ }^{\circ} \mathrm{C} / \mathrm{min}\right)$} & \multicolumn{3}{|c|}{$\ln K$} & \multicolumn{3}{|c|}{$n$} & \multirow{2}{*}{$R^{2}$} \\
\hline & & \pm & $\%$ & & \pm & $\%$ & \\
\hline 2 & -9.0492 & 0.0122 & 0.1 & 3.4649 & 0.0052 & 0.2 & 0.998 \\
\hline 4 & -7.2279 & 0.0176 & 0.2 & 3.1179 & 0.0084 & 0.3 & 0.995 \\
\hline 6 & -6.3746 & 0.0333 & 0.5 & 3.4215 & 0.0194 & 0.6 & 0.987 \\
\hline 8 & -3.2308 & 0.0150 & 0.5 & 3.6864 & 0.0218 & 0.6 & 0.995 \\
\hline 12 & -1.7596 & 0.0089 & 0.5 & 3.8235 & 0.0216 & 0.6 & 0.997 \\
\hline 16 & -3.0387 & 0.0203 & 0.7 & 4.9705 & 0.0445 & 0.9 & 0.993 \\
\hline 24 & -0.6115 & 0.0113 & 1.8 & 3.2684 & 0.0241 & 0.7 & 0.996 \\
\hline 32 & 1.8591 & 0.0358 & 1.9 & 2.8133 & 0.3190 & 11.3 & 0.996 \\
\hline 48 & 3.1936 & 0.0795 & 2.5 & 2.9836 & 0.0528 & 1.8 & 0.994 \\
\hline
\end{tabular}

Table A12. Ozawa parameters for PHB (C1).

\begin{tabular}{|c|c|c|c|c|c|c|c|}
\hline \multirow{2}{*}{$T\left({ }^{\circ} \mathrm{C}\right)$} & \multicolumn{3}{|c|}{$\ln \kappa$} & \multicolumn{3}{|c|}{$m$} & \multirow{2}{*}{$R^{2}$} \\
\hline & & \pm & $\%$ & & \pm & $\%$ & \\
\hline 100 & -1.3041 & 0.3460 & 26.5 & 3.3072 & 0.2530 & 7.6 & 0.994 \\
\hline 95 & 0.4196 & 0.3259 & 77.7 & 3.0466 & 0.2383 & 7.8 & 0.994 \\
\hline 90 & 1.7162 & 0.0912 & 5.3 & 3.0423 & 0.0667 & 2.2 & 0.999 \\
\hline 85 & 3.0437 & 0.0134 & 0.4 & 3.2783 & 0.0098 & 0.3 & 1.000 \\
\hline 80 & 4.1058 & 0.1313 & 3.2 & 3.4340 & 0.0960 & 2.8 & 0.999 \\
\hline 75 & 4.9685 & 0.1294 & 2.6 & 3.5352 & 0.0666 & 1.9 & 0.999 \\
\hline 70 & 3.6428 & 0.9389 & 25.8 & 2.3021 & 0.4836 & 21.0 & 0.956 \\
\hline 65 & 3.3463 & 1.2561 & 37.5 & 1.7803 & 0.6470 & 36.3 & 0.883 \\
\hline 60 & 4.9965 & 1.3386 & 26.8 & 2.4581 & 0.5786 & 23.5 & 0.900 \\
\hline 55 & 4.3003 & 0.9834 & 22.9 & 1.7609 & 0.4251 & 24.1 & 0.896 \\
\hline 50 & 2.7860 & 1.5562 & 55.9 & 0.9376 & 0.6106 & 65.1 & 0.702 \\
\hline 45 & 2.4554 & 1.7639 & 71.8 & 0.5830 & 0.6921 & 118.7 & 0.415 \\
\hline
\end{tabular}


Table A13. Ozawa parameters for PBAT (C1).

\begin{tabular}{|c|c|c|c|c|c|c|c|}
\hline \multirow{2}{*}{$T\left({ }^{\circ} \mathbf{C}\right)$} & \multicolumn{3}{|c|}{$\ln \kappa$} & \multicolumn{3}{|c|}{$m$} & \multirow{2}{*}{$R^{2}$} \\
\hline & & \pm & $\%$ & & \pm & $\%$ & \\
\hline 95 & 1.7164 & 1.6134 & 94.0 & 3.8437 & 1.1796 & 30.7 & 0.914 \\
\hline 90 & 3.1909 & 1.4853 & 46.5 & 3.8391 & 0.9424 & 24.6 & 0.893 \\
\hline 85 & 4.6403 & 1.3316 & 28.7 & 3.8933 & 0.7418 & 19.1 & 0.902 \\
\hline 80 & 4.1889 & 0.5798 & 13.8 & 2.6476 & 0.3230 & 12.2 & 0.957 \\
\hline 75 & 5.5220 & 0.4380 & 7.9 & 2.6492 & 0.2215 & 8.4 & 0.986 \\
\hline 70 & 5.8429 & 0.1053 & 1.8 & 2.2798 & 0.0493 & 2.2 & 0.999 \\
\hline
\end{tabular}

Table A14. Ozawa parameters for PHB/PBAT blend (C1).

\begin{tabular}{|c|c|c|c|c|c|c|c|}
\hline \multirow{2}{*}{$T\left({ }^{\circ} \mathrm{C}\right)$} & \multicolumn{3}{|c|}{$\ln \kappa$} & \multicolumn{3}{|c|}{$m$} & \multirow{2}{*}{$R^{2}$} \\
\hline & & \pm & $\%$ & & \pm & $\%$ & \\
\hline 85 & 3.4662 & 5.7715 & $>100$ & 3.1229 & 2.3441 & 75.1 & 0.6396 \\
\hline 80 & 5.5473 & 0.1533 & 2.8 & 3.1761 & 0.0576 & 1.8 & 0.9993 \\
\hline 75 & 5.9673 & 0.9008 & 15.1 & 2.7735 & 0.3388 & 12.2 & 0.9710 \\
\hline 70 & 6.8120 & 1.0544 & 15.5 & 2.6438 & 0.3965 & 15.0 & 0.9569 \\
\hline 65 & 10.0566 & 2.2551 & 22.4 & 3.5234 & 0.7064 & 20.0 & 0.8924 \\
\hline 60 & 8.7700 & 1.5671 & 17.9 & 2.7207 & 0.4909 & 18.0 & 0.9110 \\
\hline 55 & 6.7435 & 1.9721 & 29.2 & 1.8479 & 0.5894 & 31.9 & 0.8309 \\
\hline 50 & 8.1549 & 4.9812 & 61.1 & 1.9783 & 1.4165 & 71.6 & 0.6611 \\
\hline
\end{tabular}

Table A15. Mo parameters for PHB (C1).

\begin{tabular}{|c|c|c|c|c|c|c|c|}
\hline \multirow{2}{*}{$x(\%)$} & \multicolumn{3}{|c|}{$\ln F$} & \multicolumn{3}{|c|}{$\alpha$} & \multirow{2}{*}{$R^{2}$} \\
\hline & & \pm & $\%$ & & \pm & $\%$ & \\
\hline 10 & 4.7575 & 0.4920 & 10.3 & 1.9880 & 0.2017 & 10.1 & 0.979 \\
\hline 20 & 4.7716 & 0.4479 & 9.3 & 1.8737 & 0.1836 & 9.7 & 0.981 \\
\hline 30 & 4.7712 & 0.4109 & 8.6 & 1.8010 & 0.1684 & 9.3 & 0.982 \\
\hline 40 & 4.7799 & 0.3802 & 7.9 & 1.7500 & 0.1558 & 8.9 & 0.984 \\
\hline 50 & 4.7960 & 0.3537 & 7.3 & 1.7113 & 0.1450 & 8.4 & 0.985 \\
\hline 60 & 4.8127 & 0.3293 & 6.8 & 1.6780 & 0.1350 & 8.0 & 0.987 \\
\hline 70 & 4.8337 & 0.3120 & 6.4 & 1.6477 & 0.1279 & 7.7 & 0.988 \\
\hline 80 & 4.8634 & 0.3064 & 6.3 & 1.6184 & 0.1256 & 7.7 & 0.988 \\
\hline 90 & 4.9201 & 0.3181 & 6.4 & 1.5902 & 0.1304 & 8.2 & 0.986 \\
\hline
\end{tabular}

Table A16. Mo parameters for PBAT (C1).

\begin{tabular}{|c|c|c|c|c|c|c|c|}
\hline \multirow{2}{*}{$x(\%)$} & \multicolumn{3}{|c|}{$\ln F$} & \multicolumn{3}{|c|}{$\alpha$} & \multirow{2}{*}{$R^{2}$} \\
\hline & & \pm & $\%$ & & \pm & $\%$ & \\
\hline 10 & 2.2293 & 0.1148 & 5.1 & 0.9512 & 0.0439 & 4.6 & 0.987 \\
\hline 20 & 2.4551 & 0.0946 & 3.8 & 0.9517 & 0.0362 & 3.8 & 0.991 \\
\hline 30 & 2.5847 & 0.0826 & 3.1 & 0.9511 & 0.0316 & 3.3 & 0.993 \\
\hline 40 & 2.6773 & 0.0743 & 2.7 & 0.9497 & 0.0284 & 2.9 & 0.994 \\
\hline 50 & 2.7512 & 0.0683 & 2.4 & 0.9478 & 0.0261 & 2.7 & 0.995 \\
\hline 60 & 2.8146 & 0.0643 & 2.2 & 0.9451 & 0.0246 & 2.6 & 0.996 \\
\hline 70 & 2.8727 & 0.0628 & 2.1 & 0.9414 & 0.0240 & 2.5 & 0.996 \\
\hline 80 & 2.9304 & 0.0661 & 2.2 & 0.9359 & 0.0253 & 2.7 & 0.995 \\
\hline 90 & 2.9966 & 0.0858 & 2.8 & 0.9257 & 0.0328 & 3.5 & 0.992 \\
\hline
\end{tabular}

Table A17. Mo parameters for PHB/PBAT blend (C1).

\begin{tabular}{|c|c|c|c|c|c|c|c|}
\hline \multirow[t]{2}{*}{$x(\%)$} & \multicolumn{3}{|c|}{$\ln F$} & \multicolumn{3}{|c|}{$\alpha$} & \multirow[t]{2}{*}{$R^{2}$} \\
\hline & & \pm & $\%$ & & \pm & $\%$ & \\
\hline 10 & 3.1676 & 0.3013 & 9.5 & 1.2073 & 0.1191 & 9.8 & 0.966 \\
\hline 20 & 3.3480 & 0.2659 & 7.9 & 1.1946 & 0.1051 & 8.7 & 0.970 \\
\hline 30 & 3.4894 & 0.2649 & 7.5 & 1.1964 & 0.1047 & 8.7 & 0.970 \\
\hline 40 & 3.5855 & 0.2607 & 7.2 & 1.1957 & 0.1031 & 8.6 & 0.971 \\
\hline 50 & 3.6797 & 0.2542 & 6.9 & 1.1995 & 0.1005 & 8.3 & 0.972 \\
\hline 60 & 3.7850 & 0.2448 & 6.4 & 1.2096 & 0.0968 & 8.0 & 0.975 \\
\hline 70 & 3.8699 & 0.2456 & 6.3 & 1.2143 & 0.0971 & 7.9 & 0.975 \\
\hline 80 & 3.9569 & 0.2543 & 6.4 & 1.2188 & 0.1005 & 8.2 & 0.973 \\
\hline 90 & 4.0688 & 0.2691 & 6.6 & 1.2268 & 0.1064 & 8.6 & 0.970 \\
\hline
\end{tabular}


Appendix B. Differential form of the Mo model.

The integral form of Mo model is given by Equation (11). which expresses the cooling/heating rate $\phi$ as a function of time $\tau$ measured from the start of the crystallization event. at constant relative crystallinity $\mathrm{x}$ :

$$
\phi=F \tau^{-\alpha}
$$

$F=F(x)$ and $\alpha=\alpha(T)$ are the model parameters. In this case. $x=x(\phi . \tau)$; thus:

$$
c=\frac{\partial x}{\partial \tau} \equiv\left(\frac{d x}{d \tau}\right)_{\phi}
$$

To estimate the crystallization rate it is convenient to start with:

$$
F=\tau^{\alpha} \phi
$$

For constant Mo exponent $\alpha$. differentiation at constant cooling/heating rate :

$$
\frac{\partial F}{\partial \tau}=\frac{d F}{d x}\left(\frac{d x}{d \tau}\right)_{\phi}=\alpha \tau^{\alpha-1} \phi
$$

and elimination $\tau$ between Equations (A3) e (A4):

$$
\frac{d F}{d x}\left(\frac{d x}{d \tau}\right)_{\phi}=\alpha \phi^{1 / \alpha} F^{1-1 / \alpha}
$$

or

$$
c=\left(\frac{d x}{d \tau}\right)_{\phi}=\alpha \phi^{1 / \alpha} F^{-1 / \alpha}\left(\frac{d \ln F}{d x}\right)^{-1}
$$

Equation (A6) is the differential form of Mo for constant exponent $\alpha$. Equation (A6) may be expressed as a product:

$$
c=k(\phi) \cdot f(x)
$$

of a pseudo kinetic constant (function of $\phi$ only):

$$
k=\alpha \phi^{1 / \alpha}
$$

and a function $\mathrm{f}(\mathrm{x})$ that depends on conversion only:

$$
f=F^{1-1 / \alpha}\left(\frac{d F}{d x}\right)^{-1}
$$

For crystallinity-dependent Mo exponent. $\alpha=\alpha(\mathrm{x})$. differentiation of Equation (A3):

$$
\frac{d F}{d x}\left(\frac{d x}{d \tau}\right)_{\phi}=\phi \frac{d \tau^{\alpha}}{d \tau}=\tau^{\alpha} \phi\left[\frac{\alpha}{\tau}+\ln \tau \frac{d \alpha}{d x}\left(\frac{d x}{d \tau}\right)_{\phi}\right]
$$

or

$$
c=\left(\frac{d x}{d \tau}\right)_{\phi}=\frac{\alpha \tau^{\alpha-1} \phi}{\frac{d F}{d x}-\tau^{\alpha} \ln \tau \frac{d \alpha}{d x}}
$$

The last step consists in the elimination of $\tau$ and $\ln \tau$ between Equations (A11) e (A3); a compact form of the final results is:

$$
c=\left(\frac{d x}{d \tau}\right)_{\phi}=\frac{\alpha \phi^{1 / \alpha} F^{-1 / \alpha}}{\frac{d \ln F}{d x}+\left(1-\frac{\ln F}{\ln \alpha}\right) \frac{d \ln \alpha}{d x}}
$$

Equations (A12) is a differential form of Mo model for exponent $\alpha=\alpha(\mathrm{x})$. It is not possible to define a kinetic constant in this case. 